\title{
Scaling and spatial complementarity of tectonic earthquake swarms
}

\section{Luigi Passarellii $^{{ }^{*}}$, Eleonora Rivalta ${ }^{1}$, Sigurjón Jónsson ${ }^{2}$, Martin Hensch ${ }^{3}$, Sabrina Metzger $^{1}$, Steinunn S. Jakobsdóttir ${ }^{1,2,4}$, Francesco Maccaferri ${ }^{1}$, Fabio Corbi ${ }^{1,5}$ and Torsten Dahm ${ }^{1}$}

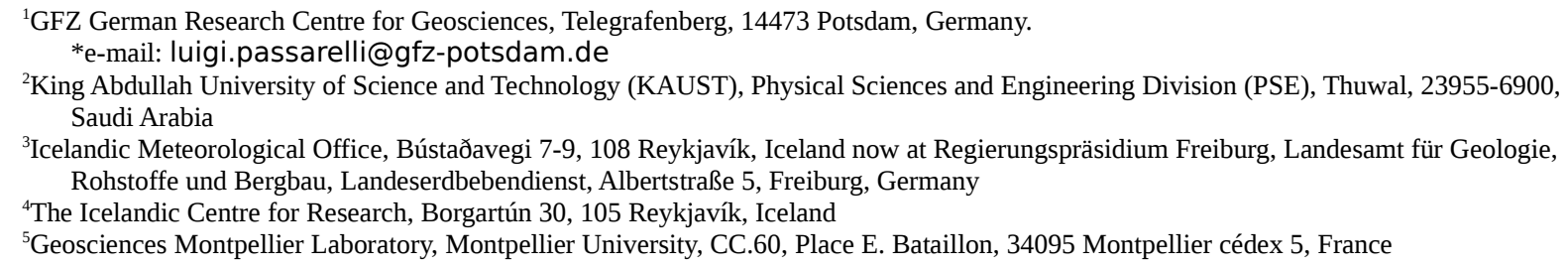

Keywords: Tectonic Earthquake Swarms (TES), Moment, duration and migration velocity scalings of TES, Efficient tectonic strain release by TES, Aseismic/seismic source mechanisms for TES, Triggering mechanisms of TES, Ridge transform fault earthquakes

\begin{abstract}
1 Tectonic earthquake swarms (TES) often coincide with aseismic slip and sometimes precede

2 damaging earthquakes. In spite of recent progress in understanding the significance and

3 properties of TES at plate boundaries, their mechanics and scaling are still largely uncertain.

4 Here we evaluate several TES that occurred during the past 20 years on a transform plate

5 boundary in North Iceland. We show that the swarms complement each other spatially with

6 later swarms discouraged from fault segments activated by earlier swarms, which suggests

7 efficient strain release and aseismic slip. The fault area illuminated by earthquakes during

8 swarms may be more representative of the total moment release than the cumulative moment

9 of the swarm earthquakes. We use these findings and other published results from a variety of

10 tectonic settings to discuss general scaling properties for TES. The results indicate that the

11 importance of TES in releasing tectonic strain at plate boundaries may have been

12 underestimated.
\end{abstract}

\section{1. Introduction}

14 Sequences of earthquakes without a clear triggering mainshock, referred to as earthquake

15 swarms, have been observed in volcanic and hydrothermal areas for decades. Tectonic 
16 Earthquake Swarms (TES) is another category of swarms linked to active tectonic regions.

17 Recent work has helped identifying some common characteristics of TES regarding their

18 release of seismic moment in time and space (Peng and Gomberg, 2010, Vidale and Shearer,

19 2006). TES have typical durations of days, weeks or months and the majority of their

20 moment release is usually delayed from the onset of the sequences (Chen and Shearer, 2011,

21 Roland and McGuire 2009, Passarelli et al. 2015). In addition, TES often migrate at velocities

22 of $1 \mathrm{~km} /$ day to $1 \mathrm{~km} / \mathrm{h}$, affecting larger volumes of rock than might be suggested by the

23 largest earthquake of the sequence (Vidale and Shearer, 2006, Lohman and McGuire, 2007,

24 Roland and McGuire, 2009). Furthermore, established earthquake scaling laws, such as the

25 Gutenberg-Richter, Omori-Utsu or Båth laws, often do not work well for swarms. TES

26 usually do not involve high magnitude events and are thought to release only an insignificant

27 fraction of the accumulated tectonic strain at plate boundaries. However, the role TES play in

28 releasing tectonic strain has rarely been quantified and remains poorly understood.

29

30 Based on deformation measurements, some TES have been linked to Slow Slip Events

31 (SSEs) (Cheloni et al., 2017, Lohman and McGuire, 2007, Vallèe et al., 2013, Villegas-Lanza

32 et al., 2016). In addition, several destructive earthquakes, including the 2009 L'Aquila, the

332011 Tohoku and the 2014 Iquique earthquakes, followed TES linked to or driven by SSEs

34 (Borghi et al., 2016, Kato et al., 2012, Schurr et al., 2014).

35

36 TES are puzzling for their apparent lack of "order”: no significant correlation has been found

37 between their moment release and their duration or migration properties (Peng and Gomberg,

38 2010, Vidale and Shearer, 2006). Peng and Gomberg (2010) noticed that the moment/duration

39 scaling of TES appears to branch off that for SSEs. However, they postulated that TES might

40 commonly hide aseismic moment, and if this moment were to be detected, e.g. by

41 deformation measurements, then the swarms would scale analogously to SSEs. This 
42 hypothesis is difficult to test, due to a lack of data on TES spanning different moment scales

43 and tectonic settings. Another issue is that seismicity catalogs are generally not long enough 44 to consider recurrence times of TES, which makes it difficult to assess their role in the 45 long-term tectonic strain budget (Passarelli et al., 2015, Cheloni et al., 2017). Usually, 46 historical information on earthquake swarms is not even included in the historical earthquake 47 catalogs (Tertulliani and Cucci, 2014).

48

49 To study further the properties of TES and define their interaction behavior over longer time 50 scales we have analyzed $\sim 20$ years of seismic data containing several well-recorded and 51 energetic TES that occurred on the Húsavík-Flatey Fault (HFF) in North Iceland. We have 52 selected the largest TES sequences and investigated their spatial and temporal organization, 53 before comparing their scaling to that of previously evaluated TES. Finally, we have 54 discussed the possible physical mechanisms behind their behaviour.

55

\section{2. Seismicity along the Húsavík-Flatey Fault and Eyjafjarðaráll Rift.} 57

58 The HFF is a 100-km-long right-lateral transform fault and a part of the wider Tjörnes

59 Fracture Zone, which links two segments of the Mid-Atlantic Ridge in Iceland, i.e. the 60 Northern Volcanic Zone to the offshore Eyjafjarðaráll Rift (ER) and Kolbeinsey Ridge (Fig. 61 1a). The HFF has been active since 7-9 Myr and probably has a cumulative displacement of 62 more than $60 \mathrm{~km}$ (Rögnvaldsson et al., 1998). At this latitude the divergence rate between the 63 North American and Eurasian plates is $\sim 18 \mathrm{~mm} / \mathrm{yr}$, of which 6-9 mm/yr is focused on the 64 HFF according to interseismic backslip modeling constrained by GPS (Metzger and Jónsson, 65 2014, Metzger et al., 2011 and 2013). Three or four magnitude 6.5-7 historical earthquakes 66 occurred on the HFF in the past 300 years with the last large earthquakes in 1872 (Fig. 1a), so 
67 the accumulated moment on the fault corresponds approximately to a magnitude 6.8-7.0

68 earthquake (Metzger and Jónsson 2014).

69

70 Earthquake locations in North Iceland are routinely determined with data collected by the

71 Icelandic National Seismic Network (SIL, Icelandic Meteorological Office), which has a

72 detection threshold ranging from magnitude 0 on the eastern HFF to magnitude 1 offshore

73 (Hensch et al., 2013). The statistical magnitude of completeness, $M_{c}$, is slightly higher, or 0.5

74 on the eastern HFF and 1.5 offshore (Maccaferri et al., 2013). Typical location errors of

75 earthquake hypocenters are of the order of a few kms with a decreasing accuracy moving

76 westward along the HFF (Hensch et al., 2013).

77

78 We relocated all 27969 earthquakes in the SIL catalog (Böðvarsson et al., 1996) from 1997

79 until 15th of July 2015 that occurred within $10 \mathrm{~km}$ from the HFF and ER (Fig. S1). We used

80 the relative location method by Slunga et al (1995) and a local seismic velocity model from

81 local earthquake tomography (LET), replacing the top $5 \mathrm{~km}$ of the layered LET model

82 (Riedel et al., 2005 and 2006) with a velocity gradient (Fig. S2). We then selected 23425

83 events with horizontal errors $<200 \mathrm{~m}$ and vertical errors $<2 \mathrm{~km}$ (Fig. S3, Jakobsdóttir et al.,

84 2013). The relocated events appear more focused and shallower than the automatic locations,

85 consistent with results from previous relocation studies of North Iceland (Rögnvaldsson et al.,

86 1998, Hensch et al., 2008). 

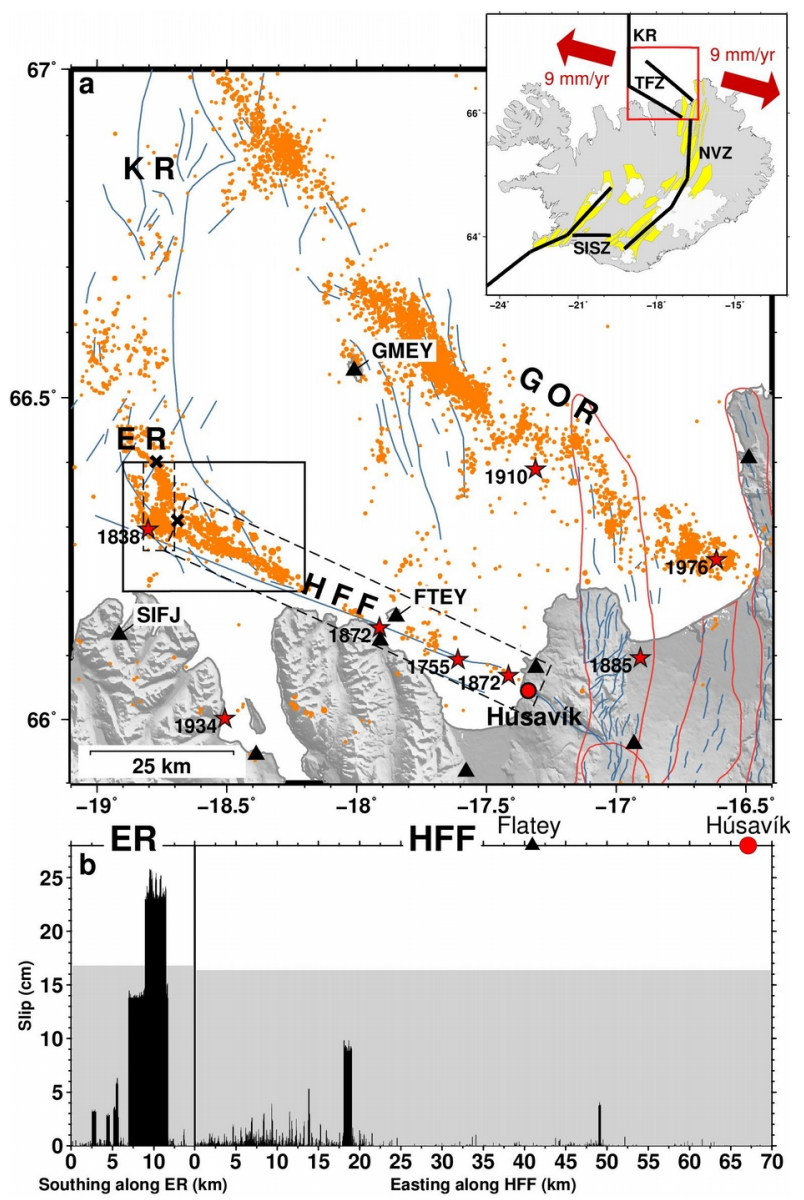

Figure 1: Earthquake locations in North Iceland and moment release long the Eyjafjarðaráll Rift (ER) and the Húsavík-Flatey Fault (HFF). (a) Earthquakes (orange dots) in the Tjörnes Fracture Zone (TFZ) primarily occur on the HFF and the Grímsey Oblique Rift (GOR). Red stars mark approximate locations of historical M>6 earthquakes, black triangles seismic and GPS (when labeled) stations, blue thin lines mapped faults and fractures, and red thin lines the outlines of fissure swarms and volcanic systems. The black rectangle marks the earthquake swarm study area shown in Fig. 2 while black dashed boxes bound the earthquakes considered in the moment release diagram in (b) with thick black crosses indicating the position of the axes origins. The town of Húsavík is indicated by a red dot. FTEY marks Flatey Island and a GPS station located there and KR stands for Kolbeinsey Ridge. Inset shows the TFZ location in North Iceland and the relative plate velocity. SISZ and NVZ stand for South Iceland Seismic Zone and North Volcanic Zone. (b) Cumulative seismic moment released by earthquakes within the rectangular dashed boxes shown in (a) around the ER and the HFF during 1997-2015 and represented as fault slip. Gray shaded areas are the slip predicted by tectonic loading at plate speed of $9 \mathrm{~mm} / \mathrm{yr}$. The slip along ER is projected on the horizontal plane and the dip angles for HFF and ER are $90^{\circ}$ and $60^{\circ}$ respectively. The rupture areas of earthquakes are calculated using standard scaling (Wells and Coppersmith 1994) and the fault width is fixed at 10 $\mathrm{km}$ for both fault segments. The scalar seismic moment of the earthquakes is derived using the moment-magnitude scaling (Kanamori and Anderson 1975) and the slip scales with moment assuming a rigidity of $30 \mathrm{GPa}$. Flatey Island (black triangle) and the town of Húsavík (red circle) are indicated for reference.

88 We estimated the cumulative seismic moment release per km on the HFF and ER since 1997

89 and compared it to the slip deficit expected for the same time interval (Metzger et al., 2013,

90 Metzger and Jónsson, 2014). Based on available focal mechanism solutions for the largest

91 earthquakes we calculated the component of the slip vector parallel to the tectonic motion and

92 the component of the fault area parallel to the plate boundary surface (Bird et al., 2002). We

93 used a shear modulus of $30 \mathrm{GPa}$ and an average seismogenic thickness of $10 \mathrm{~km}$ (Bird et al.,

94 2002, Metzger and Jónsson, 2014). From this analysis, we find that the fraction of strain 
95 released by the earthquakes varies spatially by two orders of magnitude, with $30 \%$ of the

96 strain released on the ER segment, but only 3\% on the northwestern-most part of the HFF and

$970.1 \%$ on the remaining part of the fault (Fig. 1b). Full locking of the eastern HFF is consistent

98 with analysis of the stress shadow casted by the 1975-1984 Krafla rifting episode, which

99 involved a sequence of 19 dike intrusions that compressed the easternmost portion of the fault

100 abating the seismic activity (Rögnvaldsson et al., 1998, Maccaferri et al., 2013, Passarelli et 101 al., 2014).

102

\section{3. Swarm activity}

104 Several energetic seismic swarms have been recorded on the HFF since 1997 when a 105 permanent seismic network was installed in North Iceland. We isolated the main swarms as 106 clusters of activity exceeding the average background rate by more than 10 standard 107 deviations (beta statistics introduced by Matthews and Reasenberg, 1988). We used a 108 declustered catalog (Reasenberg, 1985) and non-overlapping time windows of 30 days 109 (Matthews and Reasenberg, 1988). We identified six time periods, robust to the choice of 110 window length and the use of overlapping or non-overlapping time windows, that match the 111 seismic cluster requirement (Fig. 2). Based on a spatial and temporal analysis of the 112 seismicity around these time periods we isolated six swarms, all in the westernmost portion 113 of the HFF and along the ER (Fig. 3a). We labeled the swarms SW1 to SW6 (Figs. 2 and 3a, 114 and Table S1 in the supplementary material).

116 The two most energetic swarms occurred in 1997 and 2012 (SW1 and SW5) with two and 117 four $\mathrm{M}>4.5$ earthquakes, respectively. These swarms consist of several temporally and 118 spatially separated migrating event bursts, eight for SW1 (labeled A to H in Table S1 and Fig. 119 3c) and three for SW5 (A to C, Table S1). Swarm SW3 also shows two spatially separated 120 bursts (i.e. A to B, Table S1). In total we identified 13 bursts within the six swarms, with 
121 durations ranging from $12 \mathrm{~h}$ to 2 weeks, cumulatively occupying $25 \mathrm{~km}$ long section of the

$122 \mathrm{HFF}$ and $15 \mathrm{~km}$ of the ER. The total seismic moment released by the selected swarms is

$1234.5 \times 10^{17} \mathrm{Nm}$ (Table S1), which is $99 \%$ of the entire seismic moment released along the HFF

124 and ER during the 18-year study period (Table S1).

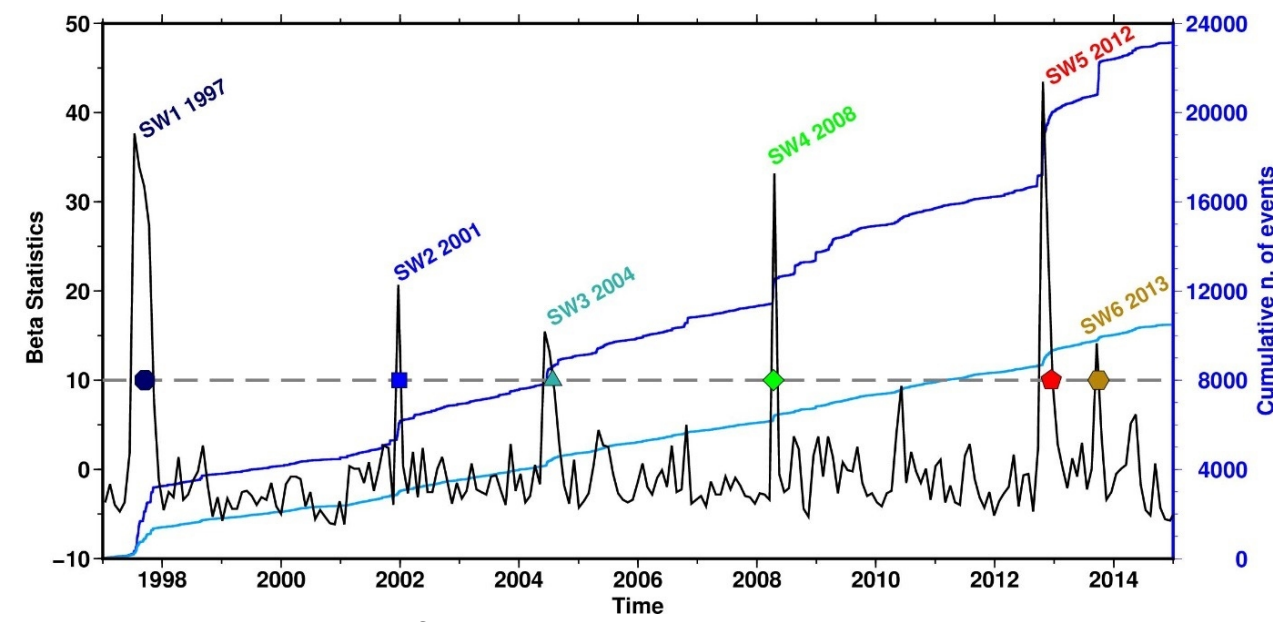

Figure 2: Earthquake swarm identification results using beta statistics. Black line is the beta statistics calculated in 30 days non-overlapping time windows. The horizontal dashed line shows the 10x standard-deviation threshold used to identify anomalies in the seismicity rate with colored symbols and labels marking selected swarms. The dark and light blue lines show the cumulative number of earthquakes in the original and declustered catalogs, respectively.

126 We further calculated best fitting focal mechanisms for the strongest events within each burst

127 of seismicity, based on P-wave polarity readings and P, SV and SH amplitudes (Rögnvaldsson

128 and Slunga, 1993). Our focal mechanism solutions show that analyzed events in swarms

129 SW1A-H, SW2, 3A, 4 and 6 are all predominantly strike-slip earthquakes while event

130 mechanisms in swarms SW3B and SW5A-C, which occurred on the ER, range from oblique

131 strike-slip to N-S striking normal faulting (Fig. 3a and Table S2). The focal mechanisms are

132 similar within each burst but differ slightly between consequent bursts, suggesting that the

133 bursts occurred on distinctive approximately planar fault segments with somewhat different

134 strikes.

136 The swarms cluster tightly on multiple distinct fault strands and appear spatially 137 complementary, both in map view and when projected on a vertical plane along the HFF 138 surface trace (Fig. 3a-b). Later swarms have filled in the gaps left behind by earlier swarms 
139 and together over the 20-year period the swarms have illuminated most of the southern ER

140 and northwestern HFF. This activity pattern suggests efficient moment and-strain release by

141 the swarms (strain release of magnitude similar to, or larger than, that accumulated over the

14220 years time scale of the seismic catalog), as the subsequent seismicity appears discouraged

143 from areas where swarms have already occurred (Wei et al. 2013). When zooming into SW1

144 (Fig. 3c-d), we find that the spatial complementarity also applies for the bursts of each

145 swarm, suggesting scale invariance. The seismicity, after occupying a fault segment in a

146 burst, jumps to another segment (not necessarily an adjacent segment) that had not ruptured

147 before, and then to another one until an entire larger segment is activated. The same pattern is

148 observed for SW5. Moreover, SW5 included a small burst (i.e. SW5C) immediately east of

149 SW1 (easternmost red cluster in Fig. 3a-b), while the fault segments in-between, activated 15

150 years earlier by SW1, remained silent.

151

152 We quantify the deviation of the sequences from mainshock-aftershock sequence scaling by

153 calculating the skewness of the moment release in time (Roland and McGuire, 2009, Chen

154 and Shearer, 2011). In contrast to mainshock-aftershocks sequences, for which the moment

155 distribution in time is highly left-skewed (most moment is released by a mainshock at the

156 onset of the sequence resulting in skewness $>>8$ (Roland and McGuire, 2009)), during

157 earthquake swarms the seismic moment release is often delayed from the swarm onset,

158 resulting in a small or negative skewness. For our six swarms (SW1-6) we find

$159-4<$ skewness $<4$ (Figure S4), consistent with other previously published swarms (Roland and

160 McGuire, 2009, Chen and Shearer, 2011). When considering the bursts individually, three

161 bursts show higher skewness up to 8.6 (SW1A, SW1F and SW5B). In spite of these

162 relatively high skewness values, these bursts still deviate from mainshock-aftershock

163 sequences since the dominant moment release was linked to at least two large events of 
164 comparable magnitude. For example, SW5B involved two M>5 within 12 hours from its

165 beginning (supplementary Figs. S5 and S6).

166

We also checked the magnitude-frequency scaling of the individual swarms, of the

167 entire catalog and of the catalog with swarms removed (Fig. S7). The Gutenberg-Richter

168 relationship is a good model in all cases, with a power law fitting well the

169 frequency-magnitude distribution. The individual swarms have b-values in the range 0.8-1.6,

170 somewhat increasing to the West, while the overall seismicity, both including and excluding

171 the TES, has b-value very close to 1 (see also Maccaferri et al., 2013).
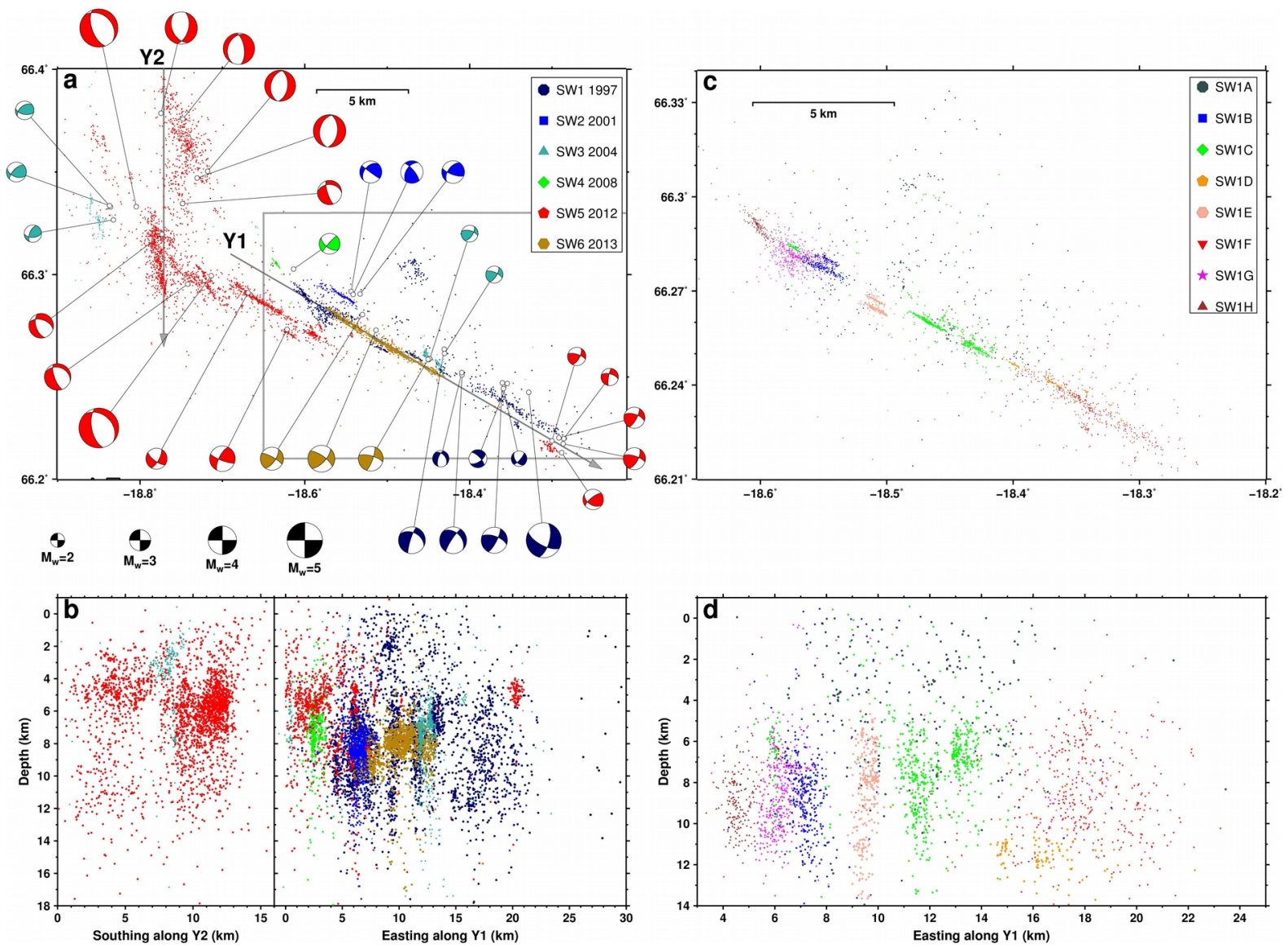

Figure 3: Spatial complementarity of earthquake swarms on the HFF and ER. Swarm event locations 1997-2015 in (a) map view and (b) in depth cross-sections along axes Y2 and Y1. Events and focal mechanisms are sized and color-coded according to size and the swarm they belong to, respectively. The two largest earthquake swarms (SW1 and SW5) consisted of several individual bursts (Table S1). (c)-(d) same as panels (a)-(b), except for the 1997 earthquake swarm (SW1) and its eight separate bursts. The black dashed box in (a) outlines the area covered in (c).

173 We next look into the earthquake migration pattern within each burst. In some cases, the first

174 earthquake locations are scattered before focusing on one fault strand of the HFF (see e.g. 
175 SW1A). In other cases, Fthe earthquakes remain small at first and concentrate near the center

176 of an activated fault segment and then migrate concentrically outwards with increasing 177 average magnitude (Fig. 4, see also Figs. S5 and S6 in the supplement for all the swarms.

178 Most of the migrations accelerate at first and then terminate abruptly (Fig. 4a-c, Fig. S5); the

179 activity then jumps to another fault strand. While all the bursts show a sharp and 180 unambiguous migration onset (supplementary Fig. S5 and S6 and Table S1), it is more 181 difficult to determine the end of each migration: we take it as the time when the earthquake 182 front reaches the maximum along-strike distance (Table S1). We then calculate the average 183 migration velocity for the bursts as the migration distance over its duration (Table S1). Such 184 average velocities, however, are not fully representative of the migration process, as 185 additional details such as differences between along-rake and along-strike migrations and 186 existence of multiple phases with different velocities are visible (Fig.4 and S5-S6). Therefore, 187 we also estimate the maximum and minimum migration velocity for each burst (details are in 188 the supplementary Table S3).

189

190 The average migration velocities range from $1 \mathrm{~km} /$ day to $1 \mathrm{~km} / \mathrm{h}$ (Table $\mathrm{S} 3$ in the 191 supplement), similar to that of previously identified migrating TES (Roland and McGuire, 192 2009). The migration appears faster in the rake direction, i.e. faster horizontally for strike-slip 193 segments and faster vertically for normal-faulting bursts (Fig. 4, S5, and S6, Table S3). 

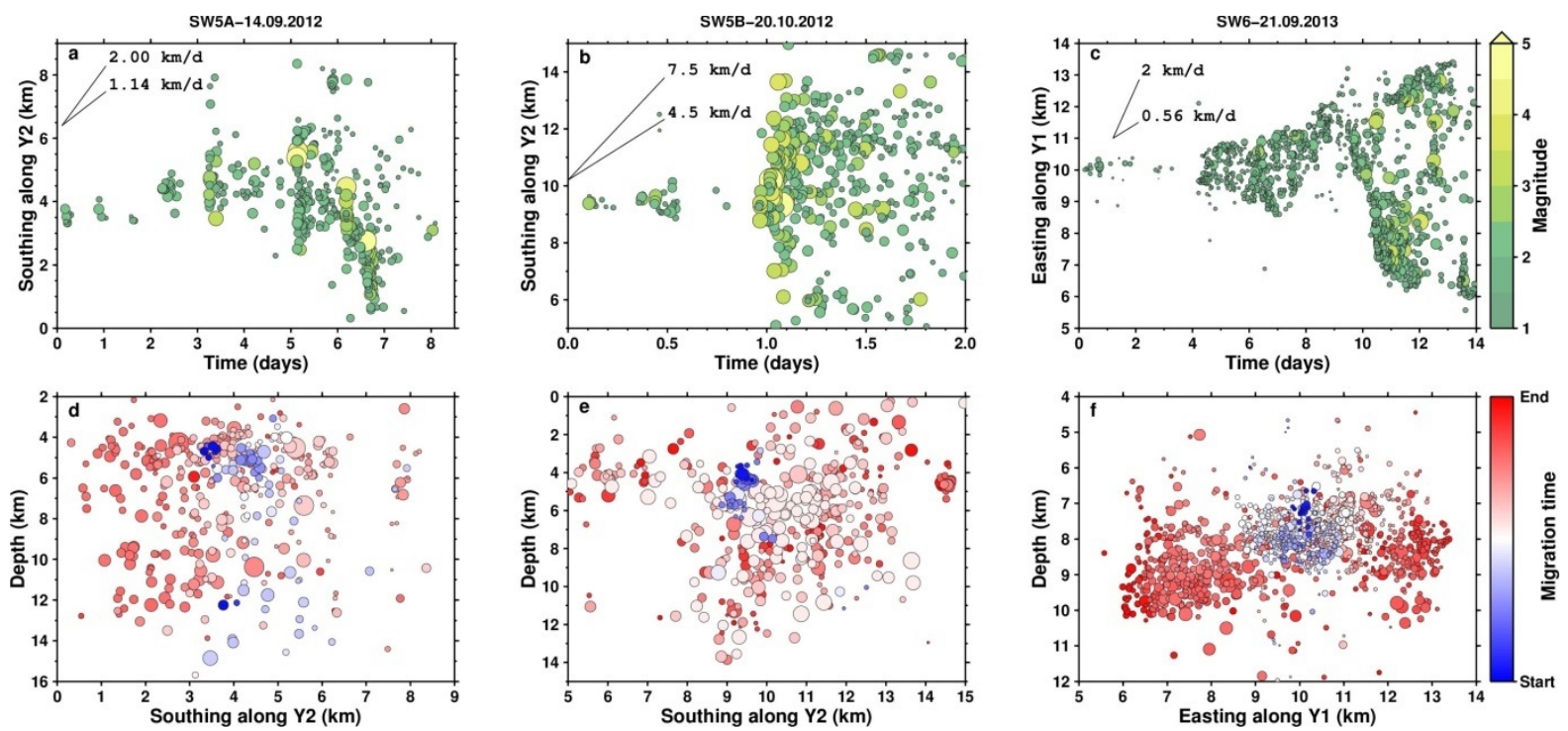

Figure 4: Migration of selected earthquake swarms. The upper panels (a-c) show the event migration along axes Y1 or Y2 (see Fig. 2) versus time, color-coded according to event magnitude, while bottom panels (d-f) show the migration in depth cross-section along Y1 or Y2, color-coded according to time. The maximum and minimum migration velocity is indicated in the upper panels (see also Table S3).

195 Accelerated or even constant-speed hypocenter migrations that then end abruptly are not

196 consistent with diffusive processes, which advance as a square root of time and fade off

197 slowly. Rather, the migration pattern suggests that the bursts mark a rupture process

198 comprising a slow nucleation phase followed by a breakout phase (Ohnaka and Shen, 1999,

199 Bouchon et al., 2013). The earthquakes may be generated by brittle asperities punctuating

200 velocity-strengthening or heterogeneously stressed fault surfaces, as previously suggested

201 (Kato et al., 2012, Lay et al., 2012, Vallée, et al., 2013). Under this hypothesis, we use the

202 estimated duration, the average rupture velocity and the cumulative seismic moment of each

203 burst to investigate the swarm scaling properties.

205 When comparing these dynamic parameters to the scaling previously reported for slow slip 206 events and TES (Gao et al., 2012, Ide et al., 2007, Peng and Gomberg, 2010) we find that our 207 data confirm and extend the scaling proposed by Peng and Gomberg (2010), according to 208 which TES duration-moment scaling branches off the SSE scaling, with TES duration 209 independent of seismic moment (Fig. 5a). In contrast to SSEs, whose propagation velocity 
210 scales as $\mathrm{M}_{0}{ }^{-1 / 2}$, the migration velocity of TES appears correlated with the seismic moment,

211 with an approximate scaling exponent of $\sim 1 / 3$ (Fig. 5b). The uncertainty of the estimated

212 scaling exponent is large but it could be reduced in future investigations with larger datasets.
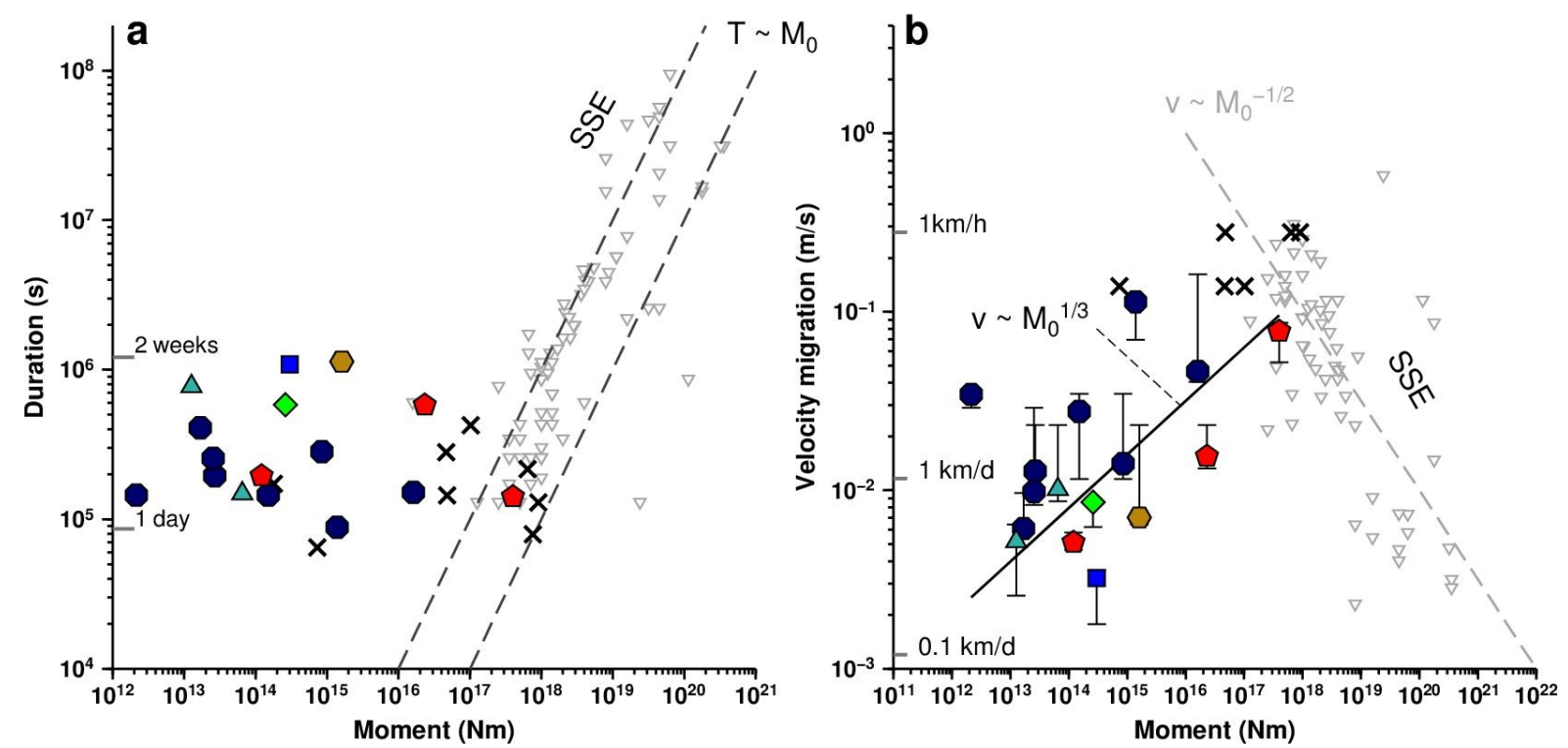

Figure 5: Scaling of tectonic earthquake swarms. (a) Event duration versus moment and (b) migration velocity versus moment for the swarms in this study (color-coded as in Fig. 2) and swarms in Peng and Gomberg 2010 (black crosses) in comparison to SSEs (gray inverted triangles) according to Gao et al. 2012. In panel (b) the black straight line is the scaling for swarm velocity and seismic moment (closed symbols).

214 TES activate larger areas compared to what might been expected from their cumulative

215 seismic moment. This results in a static effective stress drop that is one or two orders of

216 magnitude lower than for tectonic earthquakes (Vidale and Shearer, 2006). We calculate the

217 effective stress drop, $\Delta \sigma$, for our TES using the relation: $M_{0}=\pi \Delta \sigma W^{2} L / 2$, where $M_{0}$ is the

218 static seismic moment, and $\mathrm{W}$ and $\mathrm{L}$ are fault width and length, respectively (Kanamori and

219 Anderson, 1975). We estimated $\mathrm{W}$ and $\mathrm{L}$ as the width and length of the area within which

$22080 \%$ of the swarm hypocenters are located (Table S1 and Fig. S6). The estimated $\Delta \sigma$ spans

221 the range between 0.001 and $1 \mathrm{MPa}$ (Fig. 6), lower than 1-10 MPa values for regular

222 earthquakes (Kanamori and Anderson, 1975, Gao et al., 2010). Low effective stress drop

223 during TES might indicate that aseismic deformation is behind TESs in this study (e.g.

224 Roland and McGuire, 2009, Fischer and Hainzl, 2017). 


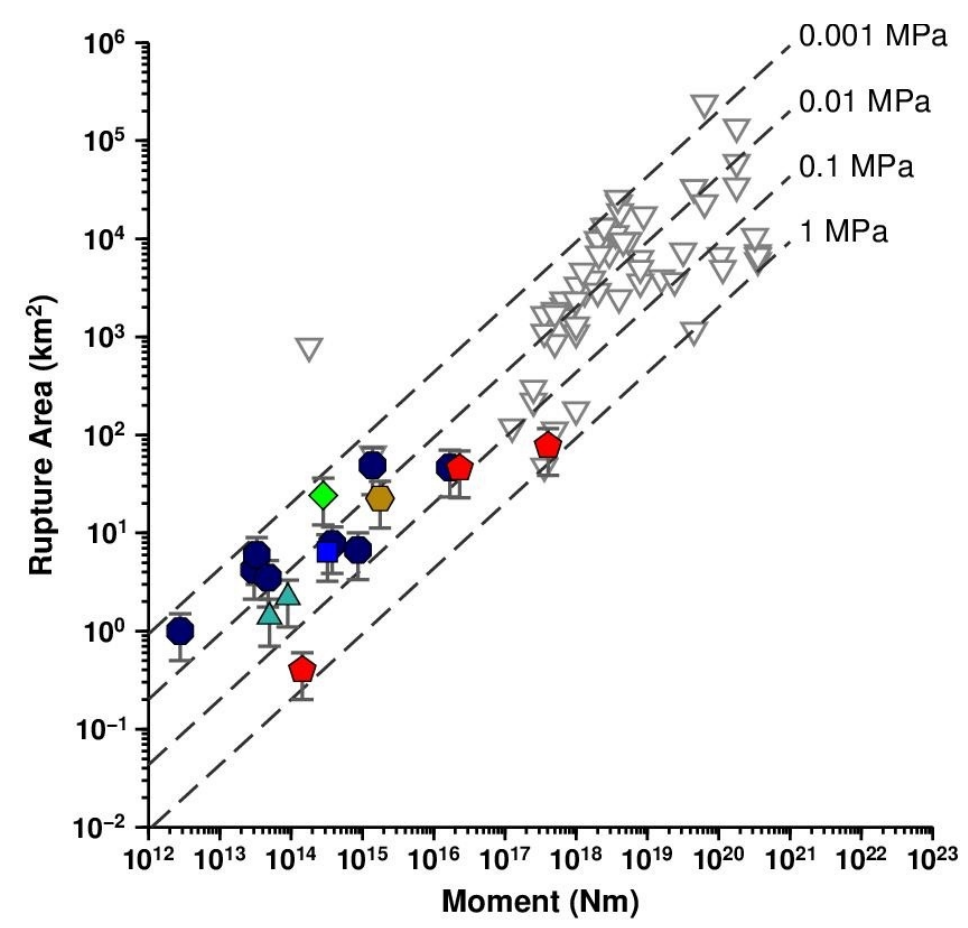

Figure 6: Static stress drop of seismic swarms along the HFF and ER. The rupture area versus the seismic moment for the swarms in this study (color-coded as in Fig. 2). Error bars are 50\% relative error on the area estimations and the rupture areas (see Table S3 and Fig. S6). Dashed lines are constant static stress drop calculated for a rectangular crack with $\mathrm{L}=2 \mathrm{~W}$ (Kanamori and Anderson, 1975). Inverted triangles show results for SSEs from Gao et al. 2012.

\section{4. Statistics of the swarm earthquakes and aseismic strain release}

227 In order to better understand the scaling of the swarm earthquakes, and their triggering 228 mechanism and their interaction with the local tectonics, we performed additional statistical 229 analysis on the seismicity catalog. Using the Epidemic Type Aftershock Sequence (ETAS) 230 model (Ogata 1988), we quantified how foreshock and aftershock productivity varies along

231 the HFF and the ER and compared the results with previous analyses of continental and 232 oceanic seismicity. ETAS models were designed to reproduce mainshock-aftershocks 233 sequences so that abnormal fitted parameters can highlight any anomalies with respect to 234 such reference behavior.

236 a combination of a magnitude-dependent productivity law:

$237 K(M)=k 10^{\alpha(M-M c)}$, 
238 (where $K$ is the number of directly triggered offspring, $k$ and $\alpha$ are region-dependent

239 parameters) and the Omori-Utsu law for seismicity-rate decay after an earthquake (Ogata,

240 1988). The average number of aftershocks per mainshock (directly and indirectly triggered) is

241 then given by the equation:

$242 N(M)=(k /(1-n)) 10^{\alpha(M-M c)}$,

243 where $b$ is the slope of the Gutenberg-Richter relation and $n=k b /(b-\alpha)$ is the so-called 244 branching ratio, representing the fraction of the earthquake population that was triggered by 245 another earthquake (Helmstetter and Sornette, 2002). Earthquake productivity is directly 246 related to the degree of crustal "brittleness", linked to seismogenic thickness and thus high

247 for continental settings and low for oceanic environments, due to more important viscoelastic 248 dissipation in the latter case. In addition, earthquake productivity is modulated by permanent 249 or transient aseismic stressing processes affecting the seismogenic crust (Helmstetter and 250 Sornette, 2002); this includes slow earthquakes, more important on ridge-transform faults 251 (RTF) than in California (McGuire et al., 2005).

252

253 For this analysis we considered the entire catalog of earthquakes close to the ER and HFF 254 with magnitudes above $\mathrm{M}_{\mathrm{c}}=1.5$, rather than restricting the analysis to only the swarm 255 seismicity. Following McGuire et al. (2005), we identified as mainshocks all $M_{\text {main }}>3.2$ events 256 that were not preceded within 2 weeks and $15 \mathrm{~km}$ by another $M>M_{\text {main }}-1.2$ earthquake. The $25715 \mathrm{~km}$ limit represents three times the rupture length of the largest events in our catalog while 258 the magnitude threshold was chosen to avoid multiple close-in-time mainshocks, which 259 would bias the fore- and aftershock counting. Indeed, the procedure excludes all the largest 260 events in SW5, i.e. the four M>4.5 earthquakes that occurred within $12 \mathrm{~h}$, and many other 261 earthquakes that occurred during 'swarmy' time periods. The identified mainshocks occurred 262 mainly on the western portion of the HFF and along the ER, while only one mainshock event 263 was recognized on the eastern HFF (Table S4). 
265 The inferred parameters $\alpha \sim 0.8$ and $n \sim 0.8$ show that the HFF and ER have aftershock 266 productivity more similar to California than to RTFs (Fig. 7a) . The high aftershock 267 productivity might be related to the thicker seismogenic crust $(10-15 \mathrm{~km}$, this study and 268 Rögnvaldsson et al., 1998) of the HFF and ER ridge-trasform segment when compared with 269 other RTFs where the seismogenic thickness is in the order of $7 \mathrm{~km}$ or thinner (e.g. Engeln et 270 al., 1986, Boettcher and Jordan, 2004).

271

272 In addition, we quantified the ratio of foreshocks to aftershocks, which has been used

273 to estimate the relative importance of aseismic forcing and earthquake-earthquake triggering 274 (McGuire et al., 2005). We find that the HFF and ER, unlike RTFs, are almost as productive 275 in terms of aftershocks as southern California faults (reaffirming the results in Fig. 7a), but 276 simultaneously they are as productive as RTFs in terms of foreshocks, i.e. they produce a half 277 order of magnitude more foreshocks than what has been observed for the southern California 278 seismicity and predicted by the ETAS model (Fig. 7b, see also McGuire et al., 2005). This 279 supports the hypothesis that transient aseismic forcing has triggered the seismicity along the 280 western HFF and ER. Future studies using more data should help reducing the statistical 281 uncertainties of the parameter estimations and help separating the different effects that 282 control earthquake productivity in Northern Iceland.

283

2845 . Constraining the aseismic strain release.

285 Based on the analyses performed above, we conclude that TES on the HFF and ER were 286 likely associated with significant transient aseismic slip. Now we seek to estimate the fraction 287 of the aseismic strain release in order to further constrain the scaling relationships of our 288 TES. 

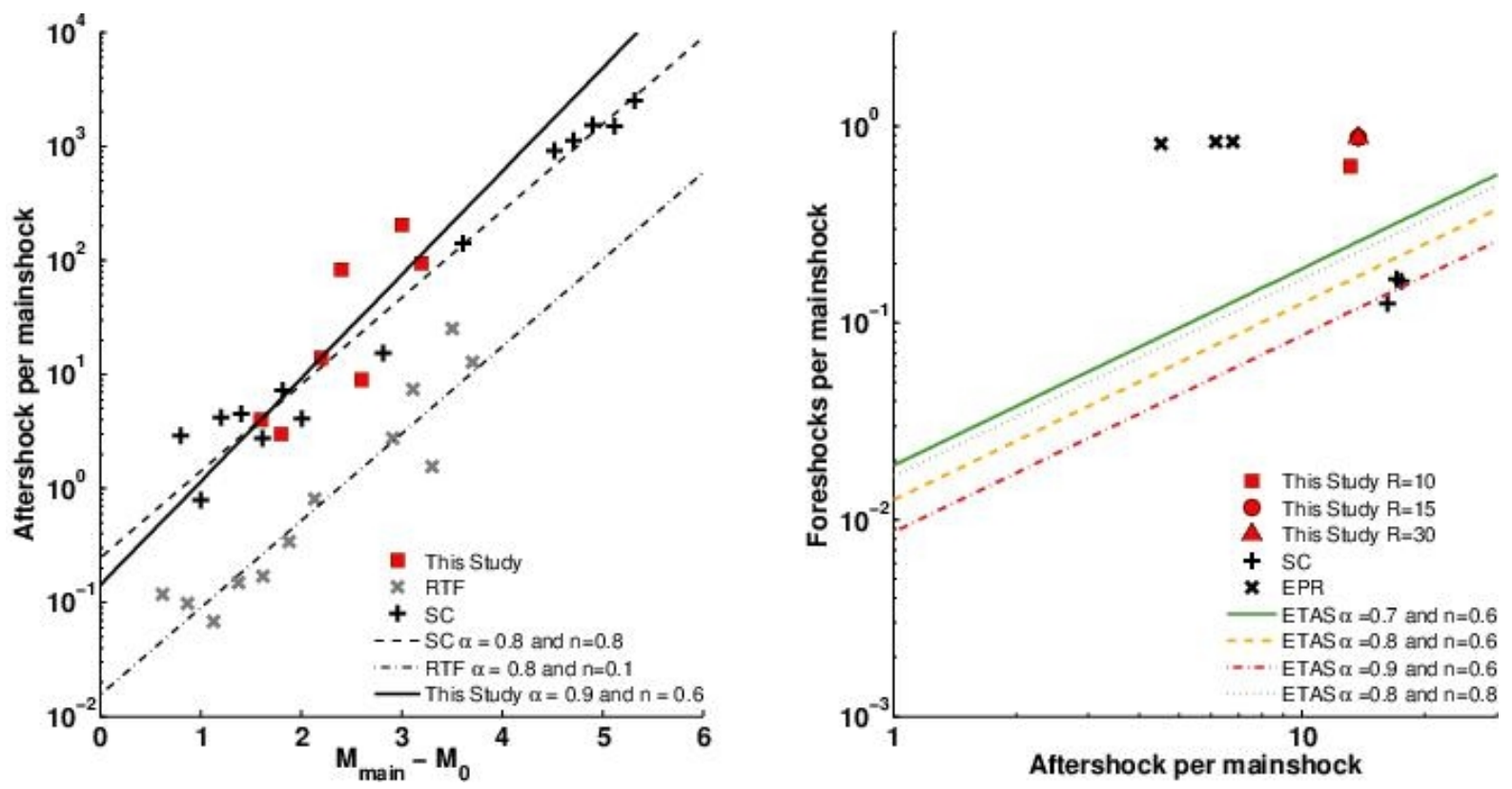

Figure 7: Scaling of aftershock and foreshock productivity along the HFF and ER. (a) Number of aftershocks per mainshock versus the mainshock magnitude $\mathbf{M}_{\text {main }}$ minus the magnitude of completeness $\mathbf{M}_{c}$. Red squares are aftershock counts along the HFF and ER above $\mathrm{M}_{\mathrm{c}}=1.5$ within 14 days and $15 \mathrm{~km}$ of all $\mathrm{M}_{\text {main }}>3.2$ mainshocks in comparison to results from southern California (SC) and ridge-transform faults (RTFs) (Boettcher and Jordan, 2004, McGuire et al. 2005). Best fits for the slope $\alpha$ and the intercept $k /(n-1)$ of $\log _{10} N(M)$ from Eq. 2 yield $\alpha=0.83, n=0.55$ ( $\alpha=0.05-1.6$ at 95\% confidence interval) for our data alone and $\alpha=0.65-0.85, n=0.55-0.80$ (95\% confidence interval) for our data together with those from southern California. (b) Number of foreshocks versus number of aftershocks per mainshock, counted during the 1h-time window before and $5 \mathrm{~h}$ after each mainshocks, in comparison to results from SC and East Pacific Rise (EPR). Straight lines are ETAS predictions as derived by McGuire et al. 2005 (eq. 1).

289 First, we check whether part of the aseismic moment release can be measured geodetically by 290 the sparse GPS network operating in North Iceland (Fig. 1a). The closest continuously 291 operating GPS stations (SIFJ, GMEY and FTEY, installed in 2006/7) are not of much help as

292 they are located $>15 \mathrm{~km}$ away from the swarms (Fig. 1a) and can therefore at best only give 293 an upper limit of the moment potentially released by the swarms. The baselines SIFJ-GMEY 294 and SIFJ-FTEY (Fig. S78) show no significant deformation signal associated with the TES, at 295 an average confidence level of 2-3 $\mathrm{mm}$ for the horizontal and 6-9 $\mathrm{mm}$ for the vertical 296 components. We checked with rectangular dislocation models in an elastic half-space (Okada, 297 1985) what could be the maximum moment release on the fault planes activated in the 2012 298 sequences without producing a significant signal in the GPS time series. The model geometry 299 was constrained manually to fit the location and spatial extent of the earthquake swarms 300 SW5A and SW5B. The segments were buried at $1 \mathrm{~km}$ depth and different slip rake angles 
301 were tested. We found that a moment larger than about $5 \cdot 10^{17} \mathrm{Nm}$ for SW5A and SW5B 302 should have been seen in the GPS time series, which is larger than the seismic moment of $3032.3 \cdot 10^{16} \mathrm{Nm}$ and $4 \cdot 10^{17} \mathrm{Nm}$ released in the swarms (supplementary Table S1). Therefore, 304 based on the GPS data we cannot exclude the possibility that some aseismic slip took place, 305 although most of the moment in SW5B appears to have been seismically released.

307 We estimated a lower limit for the stress drop of the 1997 swarm (SW1) by considering its 308 interaction with SW5. The SW1 fault segments remained silent following the two M>5 309 earthquakes in SW5B while a small fault patch adjacent and to the East of SW1 became 310 active, (the SW5C burst). The Coulomb Failure Stress ( $\triangle \mathrm{CFS}$ ) induced on the HFF by the 311 largest M>5 event of SW5B is positive on the HFF (Jónsson et al., 2013). This suggests that 312 SW5C may have been statically triggered, and that the stress drop of SW1 must have been 313 larger than the Coulomb Failure Stress change ( $\triangle \mathrm{CFS}$ ) caused by SW5B. The estimated $314 \triangle \mathrm{CFS}$ is of the order of 0.1-0.02 MPa when it is projected onto the HFF in the $1997 \mathrm{SW} 1$ 315 swarm area (see Fig. 2 in Jónsson et al., 2013). We calculated the corresponding moment with 316 the formula $M_{o}=\Delta \sigma d L W$ assuming that the fault is strained over a distance $d=5 \mathrm{~km}$ (half of 317 fault width, Madariaga 1979), and $L=20 \mathrm{~km}$ and $W=10 \mathrm{~km}$ are respectively the length and 318 width of the fault segment activated in the SW1 swarm. The resulting moment $M_{o}>0.2-1.0$ $31910^{17} \mathrm{Nm}$ ranges between the cumulative seismic moment released by SW1 and five times as 320 much (Tab. S1), which suggests that SW1 may have released additional moment 321 aseismically. Considering that the $\triangle \mathrm{CFS}$ estimate refers only to the largest earthquake, rather 322 than to the entire sequence, and that we neglected 15 years tectonic loading onto the SW1 323 segment in this calculation, we reckon this as a conservative estimate.

325 Finally, we estimate how much aseismic slip could potentially be hidden within the HFF and 326 ER bursts while remaining within the limits of 20 years of tectonic strain accumulation. The 
327 total tectonic moment accumulated along HFF and ER during the time span of the seismicity

328 catalog is $\sim 2.9 \cdot 10^{18} \mathrm{Nm}$, using $\mu=30 \mathrm{GPa}$ and the same fault geometry as in Fig. 1b. Assuming

329 that the area illuminated by the earthquakes (Fig. 6 and supplementary Table S1 and Fig. S6)

330 is representative of the total moment released by the bursts, we estimate such moment based

331 on the standard relationship $M_{w}=4.07+0.98 * \log (R A)$ linking rupture area $(R A)$ in $\mathrm{km}^{2}$ with

332 moment magnitude $\left(M_{w}\right)$ (Wells and Coppersmith 1994), in turn converted into seismic

333 moment (Kanamori and Anderson 1975). This procedure results in an estimated hidden

334 aseismic moment between 2 and 700 times larger than the relative cumulative seismic

335 moment, and amounts, if all swarms are taken together, to $2 \cdot 10^{18} \mathrm{Nm}$. This is close to the total

336 moment accumulated during 20 years of tectonic loading. Thus, under the above assumptions,

337 the TES and the associated aseismic slip have efficiently released the accumulated tectonic

338 moment.

\section{6. Discussion and conclusions}

340 The TES have progressively activated most of the northwestern HHF and the ER during the

341 almost 20 year of recorded seismicity showing a clear spatial complementarity. This raises

342 several questions: Is such complementarity unique? What are the potential underlying

343 processes leading to this behavior? What are the implications for the long-term strain release

344 on this section of the plate boundary in North Iceland?

346 Some evidence for TES occupying fault patches adjacent to previous swarms or segments 347 ruptured by large earthquakes exist (e.g. Holtkamp and Brudzinski, 2014), but to our 348 knowledge, the spatial complementarity of the North Iceland swarms, observed on a scale of 349 tens of $\mathrm{km}$ and in only 20 years, has never been described for any other regions. Similar 350 patterns of spatial complementarity are instead found at a much longer and larger spatial 351 scales for plate-boundary earthquakes, with major earthquakes sometimes occurring in 352 seismic gaps left by earlier events (Schurr et al., 2014). 
353 Given the small cumulative seismic moment released by some of our TES, the observation

354 that they discourage other earthquakes from occurring on the same fault patch while 355 encouraging new TES on adjacent patches, is difficult to explain without including an 356 additional aseismic moment release. The total estimated aseismic moment released by the

357 TES is equal to the tectonic load accumulated in 20 years and the size of the fault patches 358 illuminated by earthquakes in each swarm may be a proxy for such total seismic/aseismic 359 moment release during the TES. Our analysis suggests that TES may be a manifestation of 360 significant strain release, provoking both short and long-term stress interaction.

362 Aseismic stress release is consistent with both low stress drop and slow rupture velocity and 363 linked to low fault stiffness (Segall et al., 2010) associated to velocity-strengthening rock 364 rheology and/or low normal stress (in turn may be due to a number of reasons, including high 365 pore pressure, geometry, stress interaction). Several of these factors likely contribute to the 366 TES activity on the HFF. In the region around HFF deep fluid circulation is abundant, as 367 demonstrated by widespread release of hydrothermal fluids on the ocean floor (Hensch et al., 368 2008) and reflected in observed anomalies of seismic velocities $v_{p}$ and $v_{s}$ (Riedel et al., 2005). 369 In such conditions, the frictional strength of faults and in turn the expected level of strain 370 release is strongly controlled by the pore pressure.

372 Zencher and Bonafede (2006) demonstrated with a numerical model that fluids at 373 near-lithostatic pore pressure might propagate upward to mid-crustal levels if a deep fluid 374 reservoir below an impervious layer at the brittle-ductile transition becomes abruptly 375 connected with the overlying permeable crustal layers. The model explains several 376 observations from the South Iceland Seismic Zone, the other major transform zone in Iceland, 377 and it might plausibly apply to the HFF. Young hot rock cooling below the brittle ductile 378 transition is expected to release fluids that may pool at the rheological discontinuity. An 
379 intrusion of high pore pressure fluids would lower the threshold stress for rupture and 380 eventually the strongest asperities pinning the fault would fail. Laboratory studies and 381 numerical models show that when an unstable system fails at a low normal stress or high pore 382 pressure, the conditions for slow slip are approached (Leeman et al., 2016). The rupture 383 velocity may be limited by local pore-pressure drop due to inhomogeneous stress on the fault 384 segments and by poro-elastic coupling and dilatancy hardening (Segall and Rice, 1995, Segall 385 et al., 2010), with the small-scale asperities failing as regular earthquakes (Kato et al., 2012, 386 Gao et al., 2012). In such conditions, the 'seismic cycle' is short, as high stress levels are 387 never reached on the fault.

388 Stress interactions with the strong Krafla rifting episode on the neighboring ridge segment, 389 which occurred in the NVZ in 1975-1984, caused strong compression on the southeastern 390 HFF (Rögnvaldsson et al., 1998, Maccaferri et al., 2013) while decompressing the 391 northwestern-most part of the fault. Normal stress changes are not easily compensated by 392 tectonic movements in a transform fault setting and may thus last for long time. Static 393 decompression leads to increase of permeability, fluid release and circulation, so that the 394 swarm behavior of the northwestern HFF, contrasting the locked and quiet southeastern part 395 of the fault, might have been stimulated by static stress interaction with the NVZ.

397 Considering geometry and stress interaction may explain additional observations. The HFF is 398 composed of sub-parallel fault strands that are more or less favorably oriented according to 399 the tectonic stressing. The apparent jumps of swarms and bursts between segments may be a 400 consequence of this structural setting.

401

402 Earthquake swarms have been observed to act as barriers to large earthquake ruptures on 403 plate boundaries, leading to efficient rupture arrests (Holtkamp and Brudzinski, 2014). 404 Whether this dynamics may apply to the HFF, or whether on the contrary any future large 
405 rupture may extend to the entire fault length would be critical for local seismic hazard 406 assessments but remains unclear and challenging to determine. However, this study adds to 407 increasing evidence that TES play a previously unrecognized role in accommodating 408 long-term plate motion on plate boundaries. They embody as a specific category of slow 409 strain release that may act efficiently on shorter time scales. Evaluating them only based on 410 the seismic moment they release seismically may be misleading.

\section{Acknowledgements}

413 This work received funding from the European Union through ERC Grant N. 240583. We

414 thank Sigrún Hreinsdóttir (GNS Science) for providing the GPS time-series. The stimulating 415 comments of two anonymous reviewers helped to improve the manuscript. Data from one 416 seismometer was kindly provided by R. S. White from a project funded by the UK Natural 417 Environment Research Council (NERC) SEIS-UK (loan 968). Data retrieved in this study are 418 available in the supplementary information. The SIL earthquake catalog is available at 419 www.vedur.is. All figures except for Fig. 7 are drawn using Generic Mapping Tools software 420 (Wessel and Smith, 1998). 
423 Bird, P., Kagan, Y. Y. \& Jackson, D. D., 2002. Plate Tectonics and Earthquake Potential of

424 Spreading Ridges and Oceanic Transform Faults, in Plate Boundary Zones (eds S. Stein and

425 J. T. Freymueller), American Geophysical Union, Washington, D.C.

426 doi:10.1029/GD030p0203.

427

428

429 Böðvarsson, R., Rögnvaldsson, S. T., Jakobsdóttir, S. S., Slunga, R. \& Stefánsson, R., 1996.

430 The SIL data acquisition and monitoring system. Seismol. Res. Lett., 67, 35-46,

431 doi:10.1785/gssrl.67.5.35.

432 Boettcher, M.S. \& Jordan, T.H., 2004. Earthquake scaling relations for mid-ocean ridge 433 transform faults. J. Geophys. Res., 109(B12), doi:10.1029/2004JB003110.

434 Borghi, A., Aoudia, A., Javed, F. \& Barzaghi, R., 2016. Precursory slow-slip loaded the 2009 435 L'Aquila earthquake sequence. Geophys. J. Int. 205, 776-784, doi:10.1093/gji/ggw046.

436 Bouchon, M., Durand, V., Marsan, D., Karabulut, H., \& Schmittbuhl, J., 2013. The long 437 precursory phase of most large interplate earthquakes. Nat. Geo., 6(4), 299-302, 438 doi:10.1038/ngeo1770.

439

440 Cheloni, D., D'Agostino, N., Selvaggi, G., Avallone, A., Fornaro, G., Giuliani, R., Reale, D., 441 Sansosti, E. \& Tizzani, P., 2017. Aseismic transient during the 2010-2014 seismic swarm: 442 Evidence for longer recurrence of $M \geq 6.5$ earthquakes in the Pollino gap (Southern Italy)? 443 Sci. Rep., 7(1), pp.e576-e576, doi: 10.1038/s41598-017-00649-z.

444 Chen, X. \& Shearer,A., 2011. Comprehensive analysis of earthquake source spectra and 445 swarms in the Salton Trough, California. J. Geophys. Res. 116, doi: 10.1029/2011JB008263.

446 Engeln, J. F., Wiens, D. A., \& Stein, S. 1986. Mechanisms and depths of Atlantic transform 447 earthquakes. J. Geophys. Res., 91(B1), 548-577, doi:10.1029/JB091iB01p00548.

448 Gao, H., Schmidt, D. A. \& Weldon II, R. J. 2012 Scaling relationships of source parameters 449 for slow slip events. Bull. Seism. Soc. Am. 102, 352-360, doi:10.1785/0120110096.

450 Fischer, T., \& Hainzl, S., Effective stress drop of earthquake clusters, Bull. Seismol. Soc. Am., 451 107(5), 2247-2257, doi:10.1785/0120170035.

453 Helmstetter, A. \& Sornette, D., 2002. Subcritical and supercritical regimes in epidemic 454 models of earthquake aftershocks. J. Geophys. Res., 107(B10), doi:10.1029/2001JB001580. 455

456 Hensch, M., Riedel, C., Reinhardt, J., Dahm, T., \& The NICE-People, 2008. Hypocenter 457 migration of fluid-induced earthquake swarms in the Tjörnes Fracture Zone (North Iceland). 458 Tectonophysics, 447(1), 80-94., doi:10.1016/j.tecto.2006.07.015. 
460 Hensch, M., Guðmundsson, G.B. \& SIL Monitoring Group, 2013. Offshore seismicity with 461 large azimuthal gap: Challenges for the SIL network. In proceedings of a workshop on 462 Earthquakes in North Iceland, Húsavík, 6-8 June, 2013, Ed. G. Jóhannesdóttir et al., Húsavík 463 Academic Centre,

464 available at http://www.hac.is/wp-content/uploads/2014/04/lokaskjal_prentun_net

$465 \%$ C3\%BAtg\%C3\%A1fa.pdf.

466 Holtkamp, S. G. \& Brudzinski, M. R., 2014. Megathrust earthquake swarms indicate 467 frictional changes which delimit large earthquake ruptures. Earth Planet. Sci. Lett., 390, 468 234-243,doi:10.1016/j.epsl.2013.10.033.

469 Ide, S., Beroza, G. C., Shelly, D. R. \& Uchide, T., 2007. A scaling law for slow earthquakes. 470 Nature, 447, 76-79, doi: 10.1038/nature05780.

471 Jakobsdóttir, S., Guðmundsson, G.B., Hensch, M., \& Rivalta, E., 2013. Towards improved 472 earthquake locations in the Tjörnes Fracture Zone. In proceedings of a workshop on 473 Earthquakes in North Iceland, Húsavík, 6-8 June, 2013, Ed. G. Jóhannesdóttir et al., Húsavík 474 Academic Centre,

475 available at http://www.hac.is/wp-content/uploads/2014/04/lokaskjal_prentun_net

476 \%C3\%BAtg\%C3\%A1fa.pdf.

477

478 Jónsson, S., Metzger, S., Hreinsdóttir, S., Rivalta, E., Passarelli, L., \& Maccaferri, F., 2013. 479 The 2012-2013 earthquake sequences in North Iceland: Geodetic constraints and associated 480 stress changes. In proceedings of a workshop on Earthquakes in North Iceland, Húsavík, 6-8 481 June, 2013, Ed. G. Jóhannesdóttir et al., Húsavík Academic Centre. available at 482 http://www.hac.is/wp-content/uploads/2014/04/lokaskjal_prentun_net\%C3\%BAtg

$483 \%$ C3\%A1fa.pdf.

484

485 Kanamori, H. \& Anderson, D.L., 1975. Theoretical basis of some empirical relations in 486 seismology. Bull. Seismol. Soc. Am., 65(5), pp.1073-1095.

487 Kato, A., Obara, K., Igarashi, T., Tsuruoka, H., Nakagawa, S., \& Hirata, N., 2012.

488 Propagation of slow slip leading up to the $2011 \mathrm{Mw} 9.0$ Tohoku-Oki earthquake. Science, 489 335(6069), 705-708., doi: 10.1126/science.1215141

490 Lay, T., H. Kanamori, C. J. Ammon, K. D. Koper, A. R. Hutko, L. Ye, H. Yue, \& T. M. 491 Rushing, 2012. Depth-varying rupture properties of subduction zone megathrust faults, $J$. 492 Geophys. Res., 117, B04311, doi:10.1029/2011JB009133.

493 Leeman, J., Saffer, D. M., Scuderi, M. \& C. Marone, C., 2016. Laboratory observations of 494 slow earthquakes and the spectrum of tectonic fault slip modes. Nature Comm., 7, 495 doi:10.1038/ncomms11104.

496 Lohman, R. B. \& McGuire, J. J., 2007. Earthquake swarms driven by aseismic creep in the 497 Salton Trough, California. J. Geophys. Res., 112, doi:10.1029/2006JB004596.

498 Madariaga, R. 1979. On the relation between seismic moment and stress drop in the presence 499 of stress and strength heterogeneity. J. Geophys. Res., 84(B5), 2243-2250. 
500 Maccaferri, F., Rivalta, E., Passarelli, L. \& Jónsson, S., 2013. The stress shadow induced by

501 the 1975-1984 Krafla rifting episode. J. Geophys. Res. 118, 1109-1121,

502 doi:10.1002/jgrb.50134.

503 Matthews, M. V., \& Reasenberg, P.A., 1988. Statistical methods for investigating quiescence 504 and other temporal seismicity patterns. Pure and Applied Geophysics, 126.2, 357-372.

505 McGuire, J.J., Boettcher, M.S. and Jordan, T.H., 2005. Foreshock sequences and short-term 506 earthquake predictability on East Pacific Rise transform faults. Nature, 434(7032), 457-461, 507 doi:10.1038/nature03377.

508 Metzger, S. \& Jónsson, S., 2014. Plate boundary deformation in North Iceland during 509 1992-2009 revealed by InSAR time-series analysis and GPS. Tectonophys. 634, 127-138, 510 doi:10.1016/j.tecto.2014.07.027.

511 Metzger, S., Jónsson, S. \& Geirsson, H., 2011. Locking depth and slip-rate of the Húsavík 512 Flatey fault, North Iceland, derived from continuous GPS data 2006-2010. Geophys. J. Int. 513 187, 564-576, doi: 10.1111/j.1365-246X.2011.05176.x.

514 Metzger, S., Jónsson, S., Danielsen, G., Hreinsdóttir, S., Jouanne, F., Giardini, D., \& 515 Villemin, T., 2013. Present kinematics of the Tjörnes Fracture Zone, North Iceland, from 516 campaign and continuous GPS measurements. Geophys. J. Int., 192(2), 441-455, 517 doi:10.1093/gji/ggs032.

518 Ogata, Y., 1988. Statistical models for earthquake occurrences and residual analysis for point 519 processes. J. Am. Stat. Assoc., 83(401), pp.9-27.

520 Ohnaka, M. \& Shen, L., 1999. Scaling of the shear rupture process from nucleation to 521 dynamic propagation: Implications of geometric irregularity of the rupturing surfaces. $J$.

522 Geophys. Res., 104, 817-844, doi:10.1029/1998JB900007.

523 Okada, Y. 1985. Surface deformation due to shear and tensile faults in a half-space. Bull. 524 Seism. Soc. Am., 75(4), 1135-1154.

525 Passarelli, L., Rivalta, E., \& Shuler A., 2014. Dike intrusions during rifting episodes obey 526 scaling relationships similar to earthquakes, Sci. Rep., 4, 3886, doi:10.1038/srep03886. 527

528 Passarelli, L., Hainzl S., Cesca, S., Maccaferri, F., Mucciarelli M., Roessler, D., Corbi F., 529 Dahm T. \& Rivalta E., 2015. Aseismic transient forcing driving the swarm-like seismic 530 sequence in the Pollino range, Southern Italy, Geophys. J. Int., doi:10.1093/gji/ggv111.

531 Peng, Z. \& Gomberg, J., 2010. An integrated perspective of the continuum between 532 earthquakes and slow-slip phenomena. Nat. Geosci., 3, 599-607, doi:10.1038/ngeo940.

533 Reasenberg, P. 1985. Second-order moment of central California seismicity, 1969-1982. J. 534 Geophys. Res., 90(B7), 5479-5495.

535 Riedel, C., Tryggvason, A., Dahm, T., Stefanson, R., Böðvarson, R., \& Guðmundsson, G. B. 536 2005. The seismic velocity structure north of Iceland from joint inversion of local earthquake 537 data. J. eismol., 9(4), 383-404, doi:10.1007/s10950-005-8721-4. 
538 Riedel, C., Tryggvason, A., Brandsdottír, B., Dahm, T., Stéfansson, R., Hensch, M.,

539 Böðvarsson, R., Vogfjord, K. S., Jakobsdottír, S., Eken, T., Herber, R., Holmjarn, J., Schnese,

540 M., Thölen, M., Hofmann, B., Sigurdsson, B., \& Winter, S., 2006. First results from the North

541 Iceland experiment. Mar. Geophys. Res., 27(4), 267-281. doi: 10.1007/s11001-006-9007-0.

542 Rögnvaldsson, S. \& Slunga, R., 1993. Routine fault plane solutions for local networks: A test 543 with synthetic data. Bull. Seismol. Soc. Am. 83, 1232-1247.

544 Rögnvaldsson, S. T., Gudmundsson, A. \& Slunga, R., 1998. Seismotectonic analysis of the

545 Tjörnes Fracture Zone, an active transform fault in north Iceland. J. Geophys. Res., 103,

546 30117-30129.

547 Roland, E. \& McGuire, J. J., 2009. Earthquake swarms on transform faults. Geophys. J. Int., 548 178, 1677-1690, doi:10.1111/j.1365-246X.2009.04214.x.

549 Schurr, B., Asch, G., Hainzl, S., Bedford, J., Hoechner, A., Palo, M., Wang, R., Moreno, M., 550 Bartsch, M., Zhang, Y., Oncken, O, Tilmann, F., Dahm, T., Victor, P., Barrientos, S., \& 551 Vilotte, J. P., 2014. Gradual unlocking of plate boundary controlled initiation of the 2014 552 Iquique earthquake. Nature, 512(7514), 299-302., doi:10.1038/nature13681 .

553 Segall, P. \& Rice, J. R., 1995. Dilatancy, compaction, and slip instability of a fluid-infiltrated 554 fault. J. Geophys. Res., 100, 22155-22171.

555 Segall, P., A. M. Rubin, A. M. Bradley, \& J. R. Rice, 2010. Dilatant strengthening as a 556 mechanism for slow slip events, J. Geophys. Res., 115, B12305, doi:10.1029/2010JB007449.

557 Slunga, R., Rögnvaldsson, S. \& Böðvarsson, R., 1995. Absolute and relative locations of 558 similar events with application to microearthquakes in southern Iceland. Geophys. J. Int., 559 123, 409-419.

560

561 Tertulliani, A. \& Cucci, L., 2014. New Insights on the Strongest Historical Earthquake in the 562 Pollino Region (Southern Italy), Seismol. Res. Lett., 85(3), 743-751, 563 doi:10.1785/0220130217.

564 Vallèe, M., Nocquet, J. M., Battaglia, J., Font, Y., Segovia, M., Regnier, M., Mothes, P., 565 Jarrin, P., Cisneros, D., Vaco, S., Yepes, H., Martin, X., Bethoux, N., \& Chlieh, M., 2013. 566 Intense interface seismicity triggered by a shallow slow slip event in the Central Ecuador 567 subduction zone. J. Geophys. Res., 118(6), 2965-2981, doi:10.1002/jgrb.50216.

568 Vidale, J. E. \& Shearer, P. M., 2006. A survey of 71 earthquake bursts across southern 569 California: Exploring the role of pore fluid pressure fluctuations and aseismic slip as drivers. 570 J. Geophys. Res., 111, doi:10.1029/2005JB004034.

571 Villegas-Lanza, J. C., Nocquet, J. M., Rolandone, F., Vallée, M., Tavera, H., Bondoux, F., 572 Tran, T., Martin, X., \& Chlieh, M. 2016. A mixed seismic-aseismic stress release episode in 573 the Andean subduction zone. Nature Geoscience, 9(2), 150-154. doi: 10.1038/ngeo2620.

574 Wells, D. L., \& Coppersmith, K. J. 1994. New empirical relationships among magnitude, 575 rupture length, rupture width, rupture area, and surface displacement. Bull. Seismol. Soc. Am., 576 84(4), 974-1002. 
577 Wei, S., Helmberger, D., Owen, S., Graves, R. W., Hudnut, K. W., \& Fielding, E. J., 2013.

578 Complementary slip distributions of the largest earthquakes in the 2012 Brawley swarm,

579 Imperial Valley, California. Geophys. Res. Lett., 40(5), 847-852., doi: 10.1002/grl.50259.

580 Wessel, P., \& Smith, W. H. 1998. New, improved version of Generic Mapping Tools released.

581 Eos, Trans. Am. Geophys. Union, 79(47), 579-579.

582 Zencher, F., Bonafede, M., \& Stefansson, R. 2006. Near-lithostatic pore pressure at 583 seismogenic depths: a thermoporoelastic model. Geophys. J. Int., 166(3), 1318-1334., 584 doi:10.1111/j.1365-246X.2006.03069.x.

585 
Supplementary information

\section{Scaling and spatial complementarity of tectonic earthquake swarms}

Luigi Passarelli, Eleonora Rivalta, Sigurjón Jónsson, Martin Hensch, Sabrina Metzger, Steinunn Jakobsdóttir, Francesco Maccaferri, Fabio Corbi and Torsten Dahm 
Table S1: Parameters estimated for the tectonic earthquake swarms on the Húsavík-Flatey Fault (HFF) in 1997-2014.

\begin{tabular}{|c|c|c|c|c|c|c|c|c|c|c|c|}
\hline \multirow[b]{2}{*}{ name } & \multirow[b]{2}{*}{ Onset* } & \multicolumn{2}{|l|}{ Total } & \multicolumn{5}{|c|}{ Migration phase } & \multirow[b]{2}{*}{$\mathrm{W} / \mathrm{L}(\mathrm{km})$} & \multirow[b]{2}{*}{$\begin{array}{c}\text { Stress } \\
\text { Drop } \\
\text { (MPa) }\end{array}$} & \multirow[b]{2}{*}{ Skewness } \\
\hline & & End* & $\begin{array}{l}\text { Seismic } \\
\text { moment }^{\dagger} \\
(\mathrm{Nm})\end{array}$ & End** & $\begin{array}{c}\text { Duratio } \\
n \\
\text { (days) }\end{array}$ & $\begin{array}{l}\text { Distance } \\
(\mathrm{km})\end{array}$ & $\begin{array}{l}\text { Velocity } \\
\text { (km/day) }\end{array}$ & $\begin{array}{l}\text { Seismic } \\
\text { Moment }^{\S} \\
(\mathrm{Nm})\end{array}$ & & & \\
\hline SW1A & $\begin{array}{c}1997 / 07 / 22 \\
16: 21: 40.123\end{array}$ & $\begin{array}{c}1997 / 07 / 26 \\
05: 16: 10.952\end{array}$ & $1.3946 e+15$ & $\begin{array}{c}1997 / 07 / 23 \\
15: 54: 45\end{array}$ & 1.02 & 10.0 & 9.78 & $1.3847 e+15$ & $6.9 / 7.2$ & 0.003 & 7.6 \\
\hline SW1B & $\begin{array}{c}1997 / 07 / 28 \\
05: 13: 10.116\end{array}$ & $\begin{array}{c}\text { 1997/08/05 } \\
07: 11: 56.691\end{array}$ & $3.7857 e+14$ & $\begin{array}{c}1997 / 07 / 29 \\
20: 44: 04\end{array}$ & 1.68 & 4.0 & 2.38 & $1.5070 e+14$ & $3.2 / 2.4^{\S \S}$ & 0.010 & 1.5 \\
\hline SW1C & $\begin{array}{c}\text { 1997/08/06 } \\
04: 13: 10.409\end{array}$ & $\begin{array}{c}1997 / 08 / 22 \\
07: 48: 05.725\end{array}$ & $8.6408 e+14$ & $\begin{array}{c}1997 / 08 / 09 \\
10: 47: 23\end{array}$ & 3.29 & 4.0 & 1.22 & $8.4767 e+14$ & $3.4 / 2.0$ & 0.025 & 3.8 \\
\hline SW1D & $\begin{array}{c}1997 / 09 / 05 \\
00: 25: 04.102\end{array}$ & $\begin{array}{c}\text { 1997/09/08 } \\
04: 34: 51.199\end{array}$ & $2.7925 e+12$ & $\begin{array}{c}1997 / 09 / 06 \\
15: 57: 37\end{array}$ & 1.68 & 5.0 & 2.98 & $2.1472 e+12$ & $1.0 / 1.0$ & 0.002 & 1.6 \\
\hline SW1E & $\begin{array}{c}1997 / 09 / 09 \\
10: 42: 57.688\end{array}$ & $\begin{array}{c}1997 / 09 / 15 \\
02: 26: 18.719\end{array}$ & $3.0213 e+13$ & $\begin{array}{c}1997 / 09 / 11 \\
15: 44: 37\end{array}$ & 2.26 & 2.5 & 1.10 & $2.6682 e+13$ & $5.7 / 0.7$ & 0.001 & -0.3 \\
\hline SW1F & $\begin{array}{c}1997 / 09 / 20 \\
15: 42: 27.123\end{array}$ & $\begin{array}{c}1997 / 10 / 05 \\
23: 16: 54.629\end{array}$ & $1.6783 e+16$ & $\begin{array}{c}1997 / 09 / 22 \\
04: 02: 51\end{array}$ & 1.75 & 7.0 & 4.00 & $1.6116 e+16$ & $8.1 / 5.7$ & 0.030 & 6.4 \\
\hline SW1G & $\begin{array}{c}\text { 1997/10/20 } \\
04: 00: 18.034\end{array}$ & $\begin{array}{c}1997 / 10 / 28 \\
22: 18: 31.582\end{array}$ & $3.3087 e+13$ & $\begin{array}{c}1997 / 10 / 24 \\
17: 04: 04\end{array}$ & 4.75 & 2.5 & 0.53 & $1.6807 \mathrm{e}+13$ & $4.3 / 1.4$ & 0.001 & -0.4 \\
\hline SW1H & $\begin{array}{c}1997 / 11 / 03 \\
00: 54: 55.642\end{array}$ & $\begin{array}{c}1997 / 11 / 07 \\
05: 30: 48.038\end{array}$ & $4.7581 e+13$ & $\begin{array}{c}1997 / 11 / 05 \\
23: 05: 21\end{array}$ & 2.96 & 2.5 & 0.85 & $2.5489 e+13$ & $3.2 / 1.1$ & 0.003 & -2.0 \\
\hline SW2 & $\begin{array}{c}2001 / 12 / 12 \\
03: 59: 58.781\end{array}$ & $\begin{array}{c}2002 / 01 / 11 \\
06: 45: 25.549\end{array}$ & $3.2339 e+14$ & $\begin{array}{c}2001 / 12 / 24 \\
16: 11: 31\end{array}$ & 12.59 & 3.5 & 0.28 & $3.0148 e+14$ & $2.5 / 1.6$ & 0.020 & 1.3 \\
\hline SW3A & $\begin{array}{c}2004 / 06 / 10 \\
23: 41: 12.915\end{array}$ & $\begin{array}{c}2004 / 07 / 07 \\
05: 22: 16.569\end{array}$ & $4.9455 e+13$ & $\begin{array}{c}2004 / 06 / 19 \\
21: 59: 15\end{array}$ & 8.94 & 4.0 & 0.45 & $1.2630 \mathrm{e}+13$ & $1.5 / 0.9^{\S \S \S}$ & 0.015 & 0.9 \\
\hline SW3B & $\begin{array}{c}2004 / 08 / 26 \\
22: 52: 32.202\end{array}$ & $\begin{array}{c}2004 / 09 / 02 \\
18: 12: 38.789\end{array}$ & $8.9538 \mathrm{e}+13$ & $\begin{array}{c}2004 / 08 / 28 \\
14: 22: 38\end{array}$ & 1.72 & 1.5 & 0.87 & $6.5269 e+13$ & $2.2 / 1.0$ & 0.012 & 1.9 \\
\hline SW4 & $\begin{array}{c}2008 / 04 / 05 \\
06: 56: 27.550\end{array}$ & $\begin{array}{c}2008 / 04 / 19 \\
18: 54: 39.194\end{array}$ & $2.8237 e+14$ & $\begin{array}{c}2008 / 04 / 11 \\
22: 17: 16\end{array}$ & 6.75 & 5.0 & 0.74 & $2.6018 \mathrm{e}+14$ & $8.5 / 2.8$ & 0.001 & 1.1 \\
\hline SW5A & $\begin{array}{c}2012 / 09 / 14 \\
08: 34: 42.478\end{array}$ & $\begin{array}{c}2012 / 10 / 01 \\
06: 31: 19.280\end{array}$ & $2.3238 e+16$ & $\begin{array}{c}2012 / 09 / 21 \\
01: 07: 15\end{array}$ & 6.72 & 9.0 & 1.34 & $2.3210 \mathrm{e}+16$ & $9.3 / 4.9$ & 0.035 & 2.1 \\
\hline SW5B & $\begin{array}{c}2012 / 10 / 20 \\
02: 07: 25.596\end{array}$ & $\begin{array}{c}2013 / 03 / 13 \\
18: 10: 20.067\end{array}$ & $4.0284 \mathrm{e}+17$ & $\begin{array}{c}2012 / 10 / 21 \\
15: 06: 16\end{array}$ & 1.64 & 11.0 & 6.70 & $3.9857 e+17$ & $11 / 6.5$ & 0.326 & 8.6 \\
\hline SW5C & $\begin{array}{c}2012 / 10 / 22 \\
13: 06: 48.066\end{array}$ & $\begin{array}{c}2012 / 10 / 27 \\
02: 30: 42.536\end{array}$ & $1.4350 e+14$ & $\begin{array}{c}2012 / 10 / 24 \\
23: 34: 54\end{array}$ & 2.45 & 1.0 & 0.41 & $1.2091 \mathrm{e}+14$ & $1.5 / 0.8$ & 0.289 & 0.3 \\
\hline SW6 & $\begin{array}{c}2013 / 09 / 21 \\
04: 36: 57.614\end{array}$ & $\begin{array}{c}2013 / 10 / 08 \\
23: 14: 35.372\end{array}$ & $1.7568 \mathrm{e}+15$ & $\begin{array}{c}\text { 2013/10/04 } \\
07: 18: 19\end{array}$ & 13.14 & 8.0 & 0.61 & $1.6042 \mathrm{e}+15$ & $3.7 / 6.1$ & 0.013 & -1.2 \\
\hline $\begin{array}{l}\text { * Origir } \\
\text { ** Origir } \\
\text { extensi } \\
+ \text { Cumu } \\
\S \text { Cumu } \\
\S \S \text { W es } \\
\S \S \text { W es }\end{array}$ & $\begin{array}{l}\text { time of the first } \\
\text { time of the eartr } \\
\text { of the seismici } \\
\text { ative seismic mo } \\
\text { ative seismic mo } \\
\text { mated from the } \\
\text { imated from the }\end{array}$ & $\begin{array}{l}\text { Id last earthqual } \\
\text { uake closest in } \\
\text { ient of all earthq } \\
\text { imulative area } 7 \\
\text { umulative area } 1\end{array}$ & $\begin{array}{l}\text { in the sequen } \\
\text { he to the end o } \\
\text { akes in the swa } \\
\mathrm{km}^{2} \text { and cum } \\
\mathrm{km}^{2} \text { and cum }\end{array}$ & $\begin{array}{l}\text { he migration } \\
\text { ig the migratio } \\
\text { tive length } 2 . \\
\text { ative length } 0 .\end{array}$ & $\begin{array}{l}\text { ase meas } \\
\text { phase on } \\
\mathrm{km} \\
\mathrm{km}\end{array}$ & ed as me & mum alon & strike & & & \\
\hline
\end{tabular}


Table S2: Parameters of the focal mechanisms plotted in Fig. 3.

\begin{tabular}{|c|c|c|c|c|c|c|c|}
\hline Time & Longitude & Latitude & Depth $(\mathrm{km})$ & Magnitude & Strike & Dip & Rake \\
\hline \multicolumn{8}{|l|}{ SW1 } \\
\hline 19970806T052250.563 & -18.409 & 66.251 & 5.09 & 3.81 & 314 & 41 & -166 \\
\hline 19970807T103602.817 & -18.431 & 66.264 & 9.44 & 3.78 & 298 & 42 & -166 \\
\hline 19970920T155149.652 & -18.328 & 66.242 & 18.63 & 4.95 & 118 & 66 & -151 \\
\hline 19970928T133553.907 & -18.360 & 66.247 & 6.80 & 3.68 & 290 & 64 & 164 \\
\hline 19970711T111902.095 & -18.354 & 66.247 & 4.10 & 2.54 & 57 & 60 & -157 \\
\hline 19970710T184612.165 & -18.409 & 66.252 & 9.75 & 2.30 & 320 & 43 & -140 \\
\hline 19970710T094633.694 & -18.359 & 66.244 & 4.36 & 2.20 & 144 & 48 & -161 \\
\hline \multicolumn{8}{|l|}{ SW2 } \\
\hline 20011217T000840.648 & -18.533 & 66.291 & 7.84 & 3.20 & 215 & 53 & 24 \\
\hline 20011218T132027.535 & -18.544 & 66.292 & 9.92 & 3.11 & 220 & 43 & 5 \\
\hline 20011223T014033.287 & -18.541 & 66.290 & 11.13 & 3.18 & 215 & 48 & 158 \\
\hline \multicolumn{8}{|l|}{ SW3 } \\
\hline 20040620T192809.279 & -18.430 & 66.262 & 11.13 & 2.42 & 32 & 68 & 23 \\
\hline 20040620T201021.600 & -18.448 & 66.259 & 14.90 & 2.38 & 33 & 61 & 33 \\
\hline 20040828T085728.358 & -18.836 & 66.333 & 6.01 & 2.62 & 231 & 48 & 51 \\
\hline $20040828 T 101446.644$ & -18.837 & 66.334 & 6.46 & 2.81 & 111 & 50 & 146 \\
\hline 20040828T124157.098 & -18.832 & 66.327 & 6.22 & 2.43 & 87 & 53 & 141 \\
\hline \multicolumn{8}{|l|}{ SW4 } \\
\hline $20080408 T 232034.885$ & -18.614 & 66.303 & 10.00 & 2.94 & 127 & 59 & 172 \\
\hline \multicolumn{8}{|l|}{ SW5 } \\
\hline 20120919T075719.500 & -18.731 & 66.347 & 6.96 & 4.58 & 191 & 40 & -86 \\
\hline 20120919T082815.281 & -18.718 & 66.350 & 9.41 & 4.37 & 191 & 40 & -86 \\
\hline 20120920T092749.570 & -18.748 & 66.376 & 10.14 & 4.43 & 203 & 31 & -63 \\
\hline 20120920T194246.165 & -18.775 & 66.379 & 8.08 & 4.56 & 155 & 44 & -121 \\
\hline 20121021T001034.131 & -18.805 & 66.333 & 8.74 & 5.37 & 160 & 61 & -77 \\
\hline 20121021T002029.395 & -18.773 & 66.320 & 9.63 & 3.48 & 162 & 56 & -52 \\
\hline 20121021T003419.992 & -18.748 & 66.335 & 7.37 & 3.42 & 162 & 77 & -58 \\
\hline 20121021T012521.191 & -18.713 & 66.299 & 10.83 & 5.61 & 168 & 61 & -72 \\
\hline 20121021T013407.238 & -18.742 & 66.295 & 7.77 & 3.73 & 160 & 71 & -68 \\
\hline 20121022T052513.120 & -18.622 & 66.273 & 8.08 & 3.61 & 111 & 78 & 158 \\
\hline 20121027T220241.998 & -18.669 & 66.291 & 9.61 & 2.99 & 126 & 70 & -160 \\
\hline 20121024T024217.814 & -18.300 & 66.219 & 8.33 & 2.59 & 28 & 64 & 22 \\
\hline 20121024T102157.049 & -18.286 & 66.220 & 9.13 & 2.44 & 285 & 61 & -168 \\
\hline 20121024T221920.150 & -18.292 & 66.220 & 9.01 & 2.97 & 289 & 62 & 161 \\
\hline 20121024T222025.647 & -18.286 & 66.217 & 9.59 & 3.13 & 28 & 64 & 22 \\
\hline 20121026T194949.662 & -18.288 & 66.213 & 7.42 & 2.90 & 122 & 45 & 154 \\
\hline \multicolumn{8}{|l|}{ SW6 } \\
\hline 20131002T194025.028 & -18.514 & 66.273 & 12.63 & 3.79 & 305 & 72 & 155 \\
\hline 20131002T060517.722 & -18.530 & 66.280 & 11.00 & 3.24 & 299 & 78 & 155 \\
\hline 20131003T080448.773 & -18.450 & 66.259 & 11.07 & 3.49 & 285 & 71 & 166 \\
\hline
\end{tabular}


Table S3: Estimates of minimum and maximum migration velocity for earthquake swarms in this study.

\begin{tabular}{|c|c|c|c|c|c|c|c|}
\hline \multirow[t]{2}{*}{ Name } & \multicolumn{3}{|c|}{$\begin{array}{l}\text { Minimum estimation of } \\
\text { parameters }\end{array}$} & \multicolumn{3}{|c|}{$\begin{array}{l}\text { Maximum estimation of } \\
\text { parameters }\end{array}$} & \multirow[b]{2}{*}{ Remarks* } \\
\hline & $\begin{array}{l}\text { Duration } \\
\text { (days) }\end{array}$ & $\begin{array}{l}\text { Distance } \\
\quad(\mathrm{km})\end{array}$ & $\begin{array}{l}\text { Minimum } \\
\text { Velocity } \\
\text { (km/day) }\end{array}$ & $\begin{array}{l}\text { Duration } \\
\text { (days) }\end{array}$ & $\begin{array}{l}\text { Distance } \\
\quad(\mathrm{km})\end{array}$ & $\begin{array}{l}\text { Maximum } \\
\text { Velocity } \\
\text { (km/day) }\end{array}$ & \\
\hline $\begin{array}{l}\text { SW1A } \\
\text { (SS) }\end{array}$ & 1.00 & 6.00 & 6.00 & 1.00 & 10.00 & 10.00 & $\begin{array}{l}\text { Maximum }(10 \mathrm{~km}) \text { and minimum }(6 \mathrm{~km}) \text { extension of } \\
\text { seismicity over } 1 \text { day propagation }(0.25-1.25 \text { days in } \\
\text { Fig S5) }\end{array}$ \\
\hline $\begin{array}{l}\text { SW1B } \\
\text { (SS) }\end{array}$ & 1.00 & 1.5 & 0.67 & 1.00 & 3.00 & 3.00 & $\begin{array}{l}\text { Velocities of the two spatially separated swarms } \\
\text { (Fig.S6) at } 9.5 \mathrm{~km} \text { and } 7 \mathrm{~km} \text { along } Y \text { in Fig.S5 }\end{array}$ \\
\hline $\begin{array}{l}\text { SW1C } \\
\text { (SS) }\end{array}$ & 3.00 & 3.00 & 1.00 & 0.50 & 1.50 & 3.00 & $\begin{array}{l}\text { Minimum velocities all extension } 3 \mathrm{~km} \text { in } 3 \text { days } \\
\text { (Fig.S5). Maximum velocity starting at day } 2.5 \\
\text { lasting } 0.5 \text { day and extending for } 1.5 \mathrm{~km} \text { (Fig.S5). }\end{array}$ \\
\hline $\begin{array}{l}\text { SW1D } \\
\text { (SS) }\end{array}$ & 2.00 & 5.00 & 2.50 & 1.00 & 3.00 & 3.00 & $\begin{array}{l}\text { Maximum velocity } 1 \text { day from the start extending } \\
3 \mathrm{~km} \text { (Fig.S5). Minimum velocity is } 2 \text { days and } \\
\text { distance of } 5 \mathrm{~km} \text { (Fig.S5) }\end{array}$ \\
\hline $\begin{array}{l}\text { SW1E } \\
\text { (SS) }\end{array}$ & 2.50 & 2.00 & 0.80 & 0.50 & 1.00 & 2.00 & $\begin{array}{l}\text { Minimum velocity } 2.5 \text { days since the start extending } \\
2 \mathrm{~km} \text {. Maximum velocity is the first } 0.5 \text { day with } \\
\text { faster propagation (Fig.S5). }\end{array}$ \\
\hline $\begin{array}{l}\text { SW1F } \\
\text { (SS) }\end{array}$ & 2.00 & 7.00 & 3.50 & 0.50 & 7.00 & 14.00 & $\begin{array}{l}\text { Maximum velocity for the first } 0.5 \text { days in Fig.S5. } \\
\text { Minimum velocity same distance in } 2 \text { days starting } \\
\text { from 0.5-2.5 days in Fig.S5. }\end{array}$ \\
\hline $\begin{array}{l}\text { SW1G } \\
\text { (SS) }\end{array}$ & 5.00 & 2.50 & 0.50 & 3.00 & 2.50 & 0.83 & $\begin{array}{l}\text { Mnimum and maximum velocity of seismicity } \\
\text { considering } 5 \text { days or } 3 \text { days excluding the first } \\
\text { cluster of seismicity at days } 0-2 \text { in Fig. } 5 \text { S }\end{array}$ \\
\hline $\begin{array}{l}\text { SW1H } \\
\text { (SS) }\end{array}$ & 3.50 & 2.50 & 0.71 & 1.00 & 2.50 & 2.50 & $\begin{array}{l}\text { Minimum velocities considering the first cluster at } \\
\text { day } 0.5 \text { in Fig.S5 and maximum velocity only of the } \\
\text { cluster starting at day } 2.5 \text { in Fig.S5. }\end{array}$ \\
\hline $\begin{array}{l}\text { SW2 } \\
\text { (SS) }\end{array}$ & 13.00 & 2.00 & 0.15 & 13.00 & 4.00 & 0.31 & $\begin{array}{l}\text { Maximum and minimum extension of seismicity } \\
\text { along } Y \text { in Fig.S5. }\end{array}$ \\
\hline $\begin{array}{l}\text { SW3A } \\
\text { (SS) }\end{array}$ & 9.00 & 2.00 & 0.22 & 9.00 & 5.00 & 0.56 & $\begin{array}{l}\text { Maximum and minimum along strike extension of } \\
\text { seismicity as in Fig.S5. }\end{array}$ \\
\hline $\begin{array}{l}\text { SW3B } \\
\text { (Obl) }\end{array}$ & 2.00 & 1.50 & 0.75 & 2.00 & 4.00 & 2.00 & $\begin{array}{l}\text { Vertical (along depth Fig.S6) and horizontal (along } \\
\text { strikeFig.S5) velocities. }\end{array}$ \\
\hline $\begin{array}{l}\text { SW4 } \\
\text { (SS) }\end{array}$ & 6.50 & 3.50 & 0.54 & 6.50 & 5.00 & 0.77 & $\begin{array}{l}\text { Maximum and minimum extension of seismicity as in } \\
\text { Fig.S5 }\end{array}$ \\
\hline $\begin{array}{l}\text { SW5A } \\
\text { (NF) }\end{array}$ & 7.00 & 8.00 & 1.14 & 7.00 & 14.00 & 2.00 & $\begin{array}{l}\text { Vertical (along rake Fig.S6) and horizontal (along } \\
\text { strike Fig.S5) velocities }\end{array}$ \\
\hline $\begin{array}{l}\text { SW5B } \\
(N F)\end{array}$ & 2.00 & 12.00 & 6.00 & 2.00 & 15.00 & 7.50 & $\begin{array}{l}\text { Vertical (along depth Fig.S6) and horizontal (along } \\
\text { strike Fig.S5) velocities }\end{array}$ \\
\hline $\begin{array}{l}\text { SW5C } \\
\text { (SS) }\end{array}$ & 2.50 & 1.00 & 0.40 & 2.00 & 1.00 & 0.50 & $\begin{array}{l}\text { Duration starting from } 0.25 \text { day or from } 1 \text { day in } \\
\text { Fig.S5 over the same distance }\end{array}$ \\
\hline $\begin{array}{l}\text { SW6 } \\
\text { (SS) }\end{array}$ & 9.00 & 5.00 & 0.56 & 4.00 & 8.00 & 2.00 & $\begin{array}{l}\text { Minimum velocity from day 0-9 over a distance of } 5 \\
\mathrm{~km} \text { (first burst) in Fig.S5. Maximum velocity is from } \\
\text { day } 9-14 \text { over } 8 \mathrm{~km} \text { distance (second accelerating } \\
\text { burst) in Fig.S5. }\end{array}$ \\
\hline $\begin{array}{l}\text { * Explan } \\
\text { SS stano } \\
\text { stands fo }\end{array}$ & $\begin{array}{l}\text { on how t } \\
\text { strike-sli } \\
\text { mal mec }\end{array}$ & $\begin{array}{l}\text { maximun } \\
\text { lechanisı } \\
\text { lism fault }\end{array}$ & $\begin{array}{l}\text { d minimı } \\
\text { ult segm } \\
\text { ment. }\end{array}$ & $\begin{array}{l}\text { velocity a } \\
\text { Obl star }\end{array}$ & $\begin{array}{l}\text { stimated } \\
\text { or obliqu }\end{array}$ & echanism & ault segment and NF \\
\hline
\end{tabular}


Table S4: Mainshocks selected following the procedure described in the main text with location and aftershocks and foreshocks counts.

\begin{tabular}{ccccc}
\hline Event date & Location & Magnitude & $\mathrm{N}_{\mathrm{f}}$ & $\mathrm{N}_{\mathrm{a}}$ \\
\hline 22-Jul-1997 & HFF West & 3.99 & 0 & 9 \\
\hline 20-Sep-1997 & HFF West & 4.8 & 5 & 18 \\
\hline 09-Dec-2003 & ER & 3.30 & 1 & 2 \\
\hline 01-Nov-2006 & HFF East & 4.17 & 0 & 5 \\
\hline 29-Feb-2012 & HFF West & 3.52 & 0 & 35 \\
\hline 19-Sep-2012 & ER & 4.58 & 1 & 27 \\
\hline 10-Mar-2013 & HFF & 3.8 & 0 & 16 \\
\hline
\end{tabular}




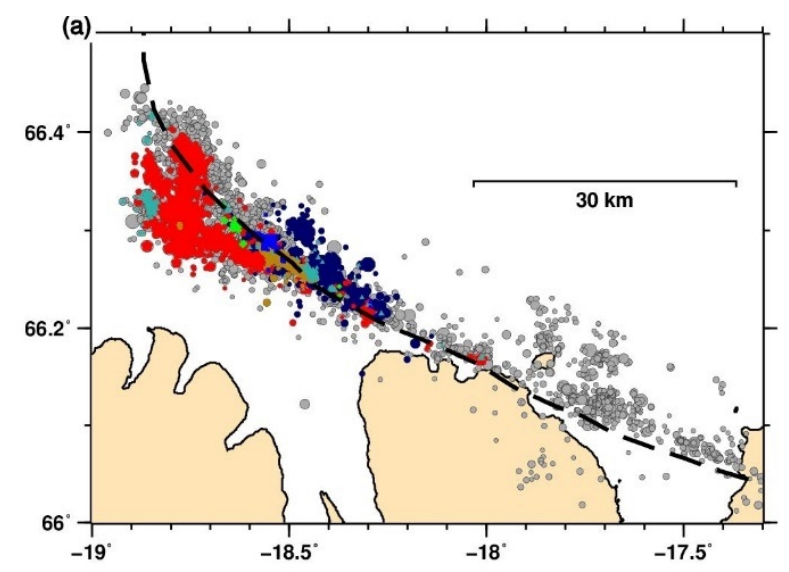

SW2 2001

A SW3 2004

SW4 2008

SW5 2012

SW6 2013

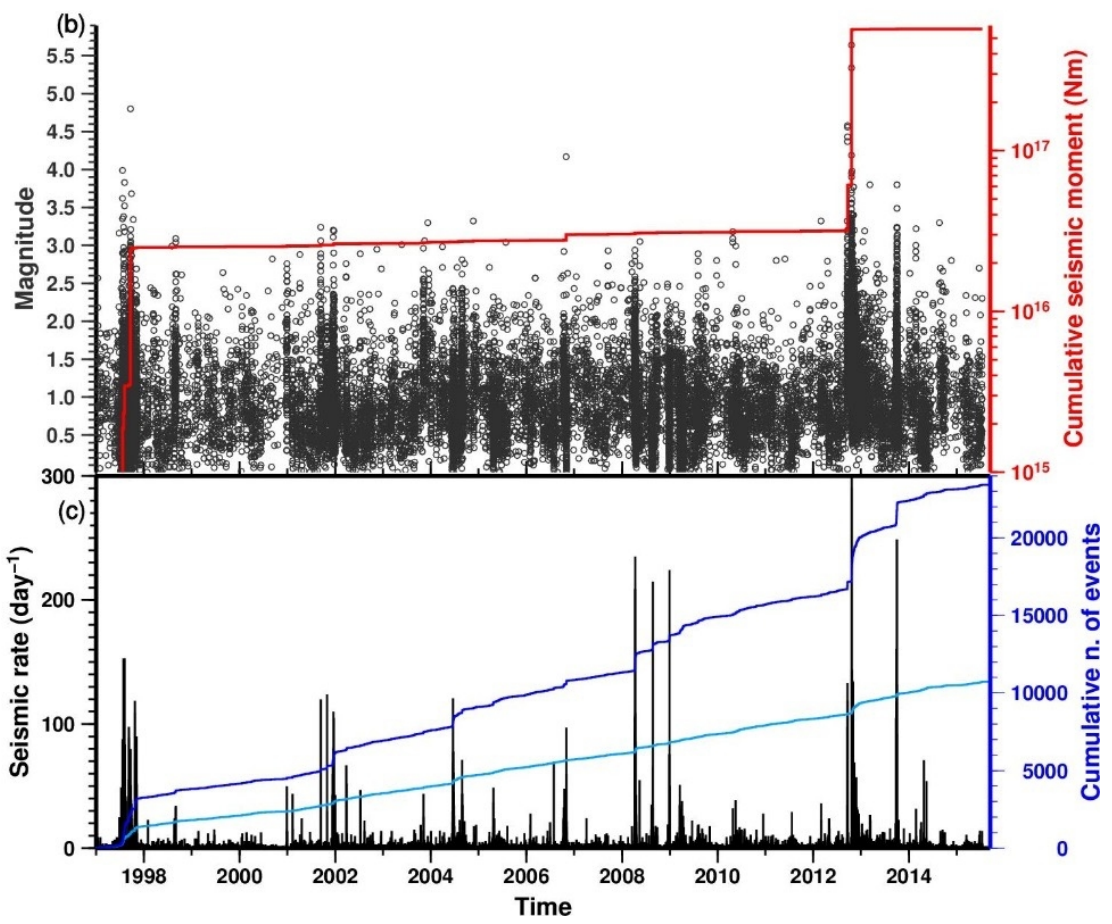

Figure S1: (a) Map of earthquakes on the Húsavík-Flatey Fault occurring during 1997-2014. Earthquakes falling within $10 \mathrm{~km}$ from the black dashed line were selected. The studied earthquake swarms are highlighted using same colors as in Figure 2 in the main text. Only events of $\mathrm{M}_{\mathrm{l}}>1$ are shown. (b): Magnitude versus time of the selected earthquakes shown in (a) with the red solid line being the cumulative moment released, assuming the local reported magnitude well represents the moment magnitude. (c): Daily rate and cumulative number of earthquakes for original catalog (blue line) and declustered catalog (light-blue line). 

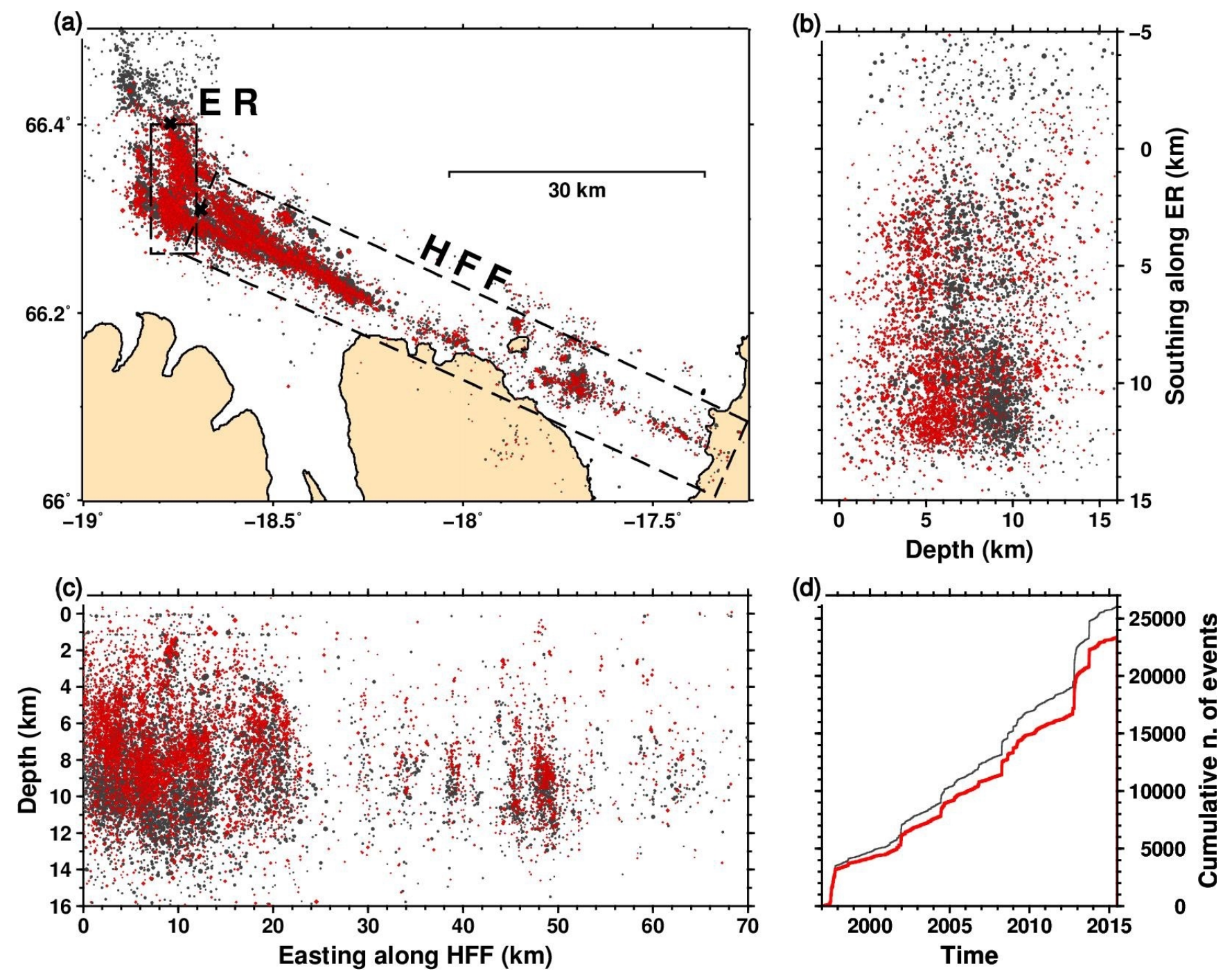

Figure S2: (a) Map of earthquakes on and near the HFF before (black dots) and after (red) relocation. Boxes represents the Cartesian coordinate system as in Fig.2 for ER and HFF and here we use to project earthquakes in panel b and c. (b-c) Depth of events as a function of distance along the long side of the boxes in panel a. Only seismicity within the box is projected. (d) Cumulative number of catalog (thin black line) and relocated events (red thick line). 


\section{Velocity-models}

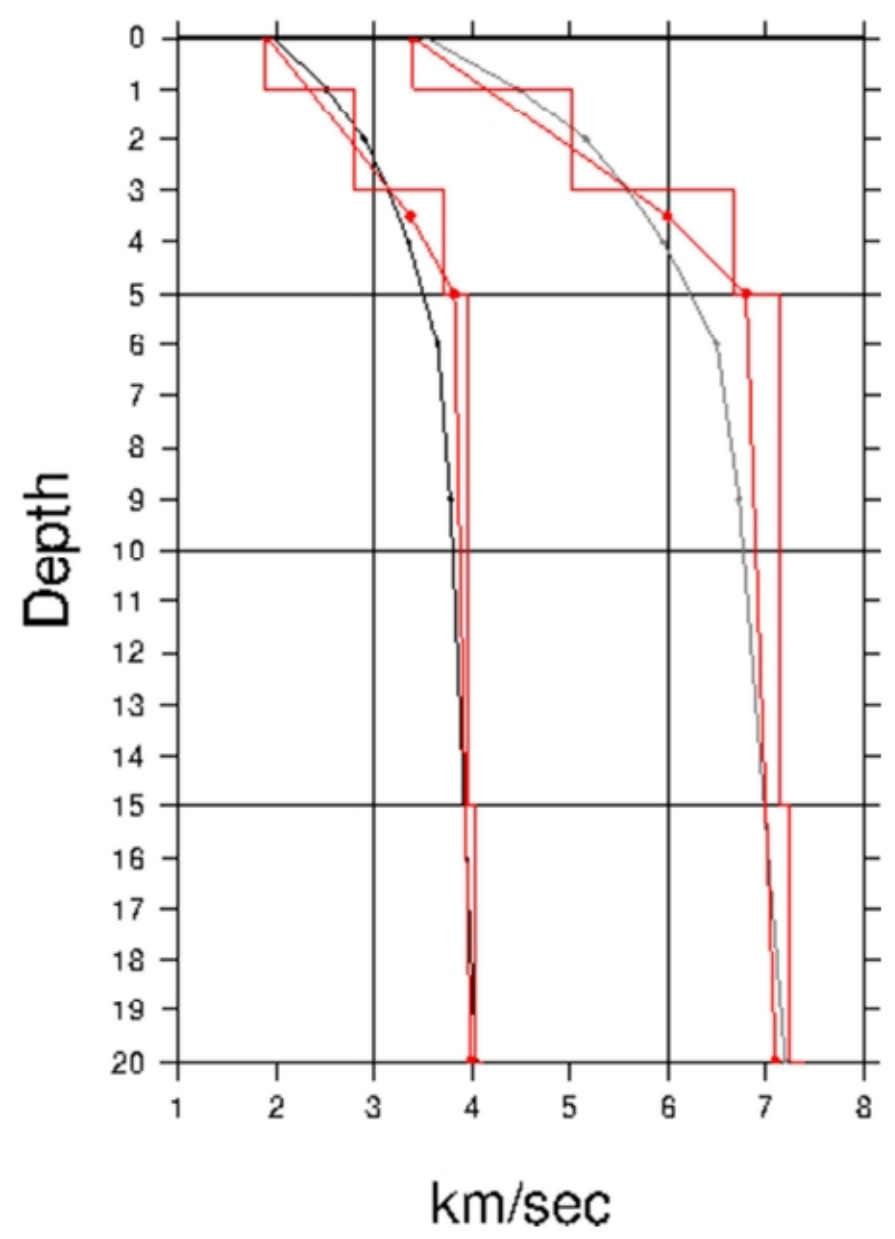

Figure S3: The crustal velocity model used to relocate the earthquakes on the Húsavík-Flatey Fault. The black lines show the SIL model that is used for routine earthquake locations in Iceland (e.g., Stefánsson et al., 1993), while red layered model is the LET model (Riedel et al. 2006), and the red gradient model was used in this study. 


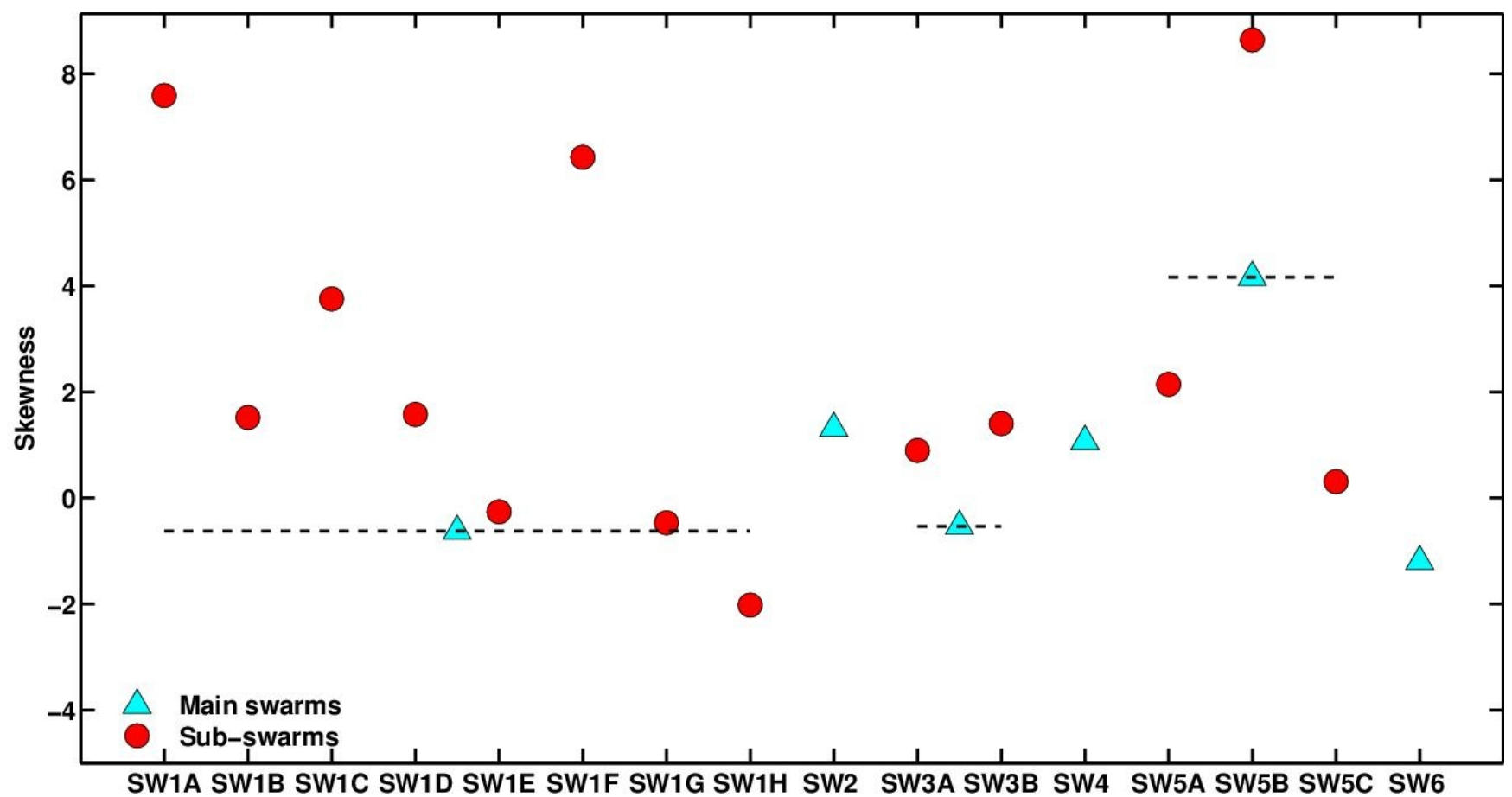

Figure S4: Skewness values of the seismic moment released in time by each swarm and burst of this study. Light blue triangles refer to the total skewness value calculated for the main swarms (SW1SW6) when considered as one sequence (indicated by the horizontal dashed line), while red circles show the skewness values of the individual bursts. 

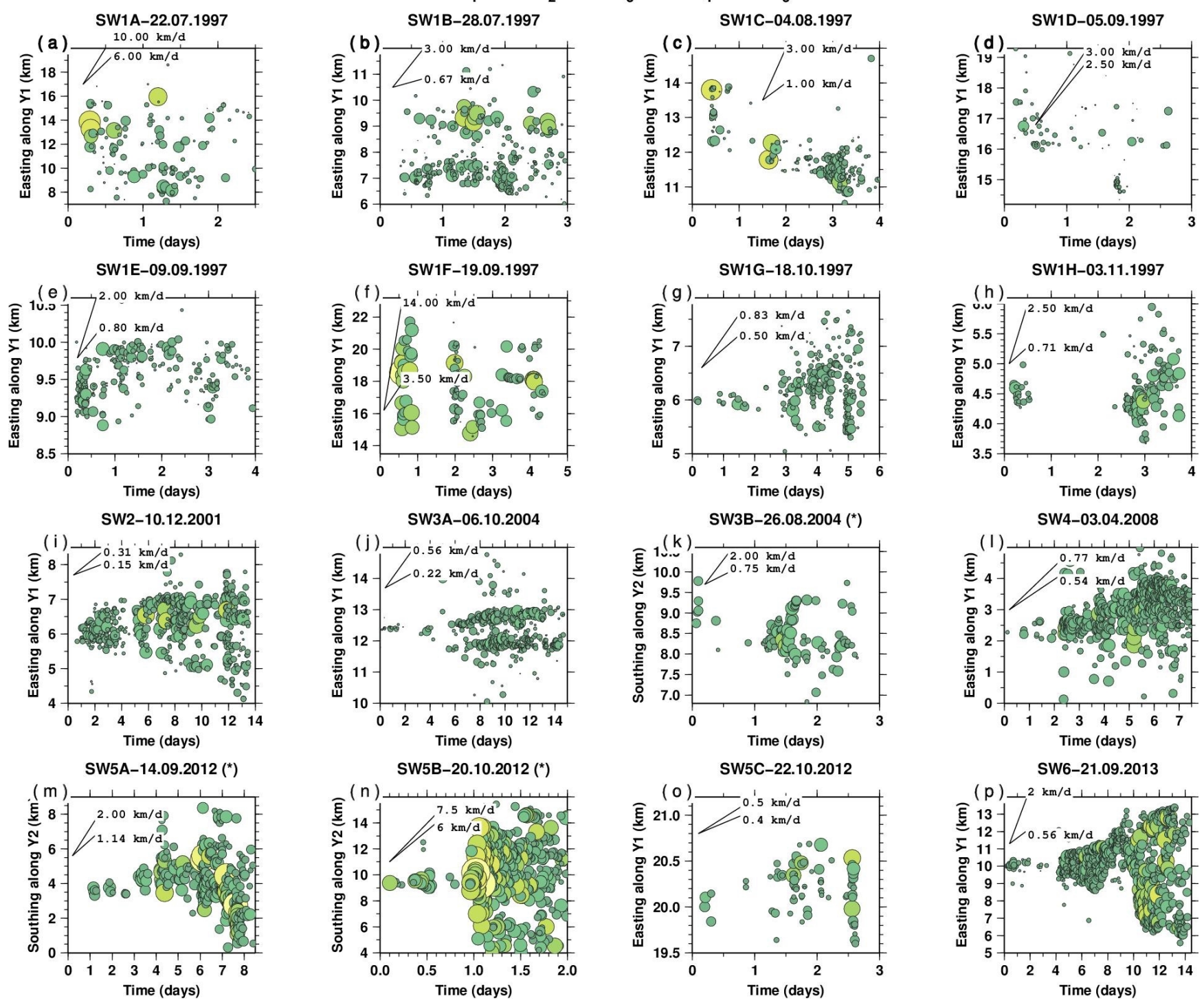

Figure S5: Location of swarm earthquakes along axis Y1 (or Y2, see Fig. 2a) versus time for the HFF swarms, with the color and size of symbols representing event magnitude. Time is shown in days from the swarm starting date reported in each panel title and in Table S1. Swarms marked with a star (panels $\mathrm{k}, \mathrm{m}$, and $\mathrm{n}$ ) occurred on normal faults. In addition, the maximum and minimum migration velocity is shown in each panel, see also Table S2. 

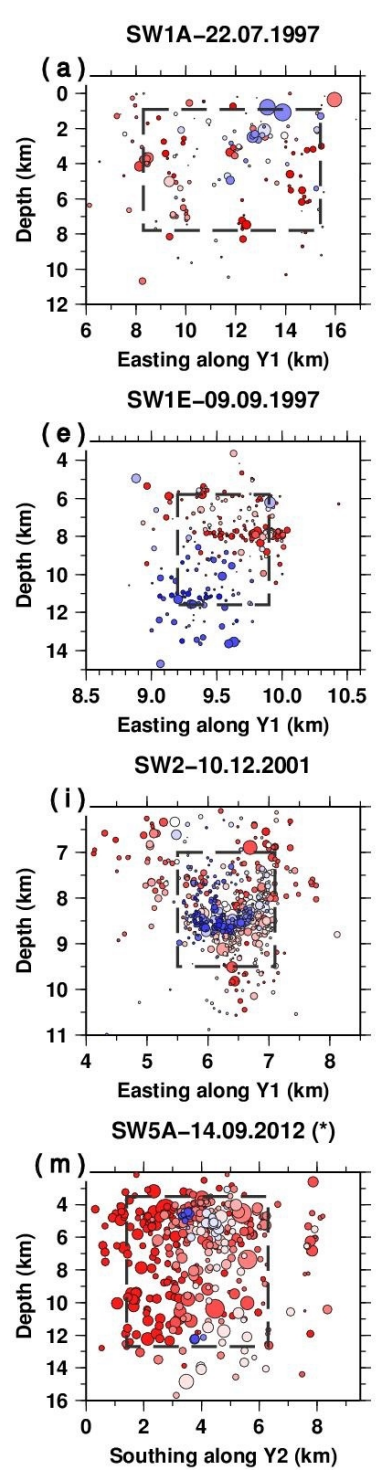

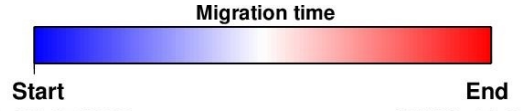

SW1B-28.07.1997

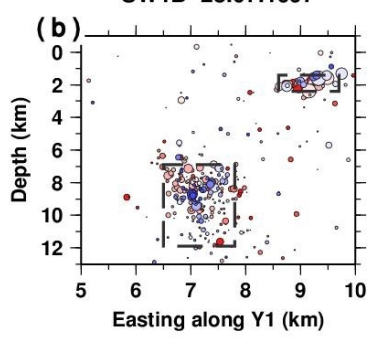

SW1F-19.09.1997
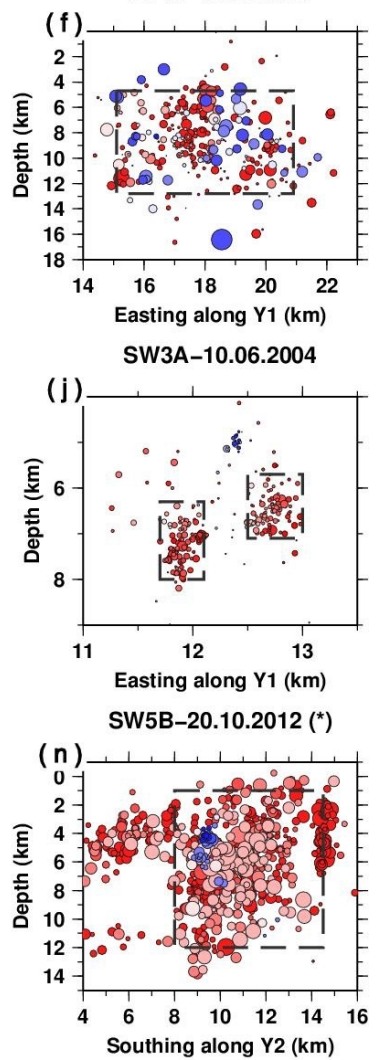

SW1C-04.08.1997

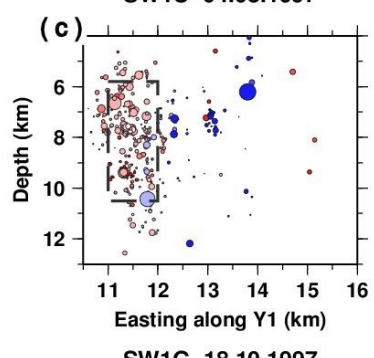

SW1G-18.10.1997
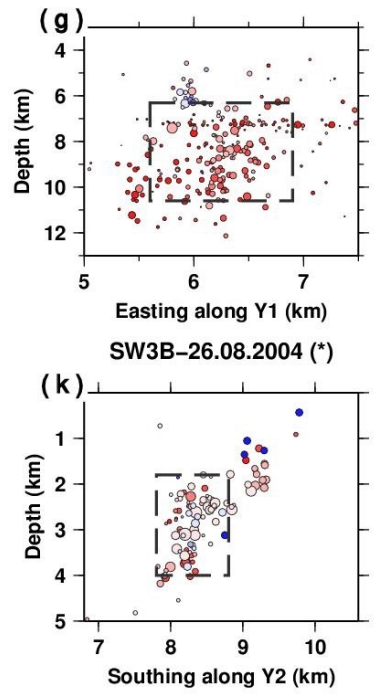

SW5C-21.10.2012

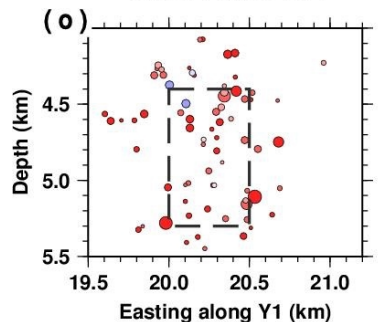

SW1D-05.09.1997

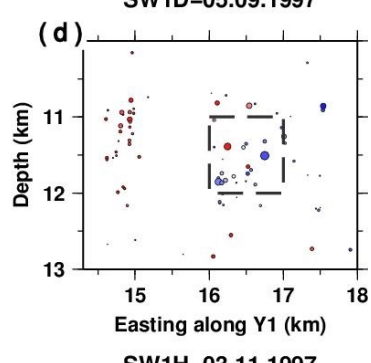

SW1H-03.11.1997

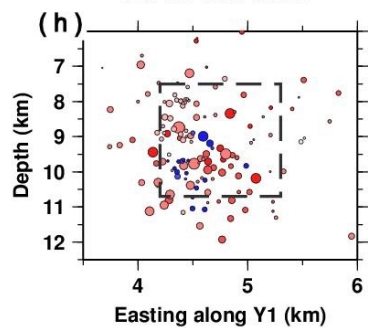

SW4-03.04.2008

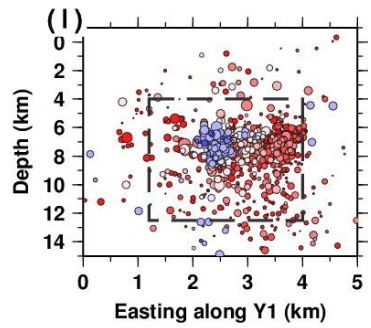

SW6-21.09.2013

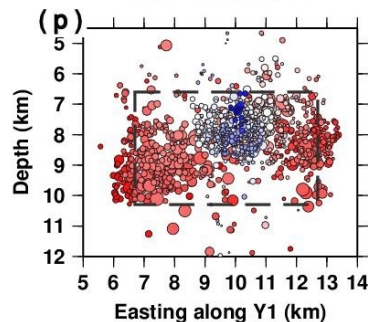

Figure S6: Depth of earthquakes as a function of distance along the Y1 (or Y2) axis shown in Fig. 2a for each of the identified earthquake swarm on the HFF. The symbol color represents time between the "Start" (blue) and the "End" (red) of each earthquake swarm, the time is reported in the x-axis in FigS5. Dashed boxes is the rupture are inferred as the area enclosing $80 \%$ of the earthquakes. Sw1B and SW3A are formed by two sub-clusters of activity and two separated boxes are accounted. Panels marked with a star (k, m, and $\mathrm{n}$ ) indicate earthquake swarms that occurred on normal faults. 

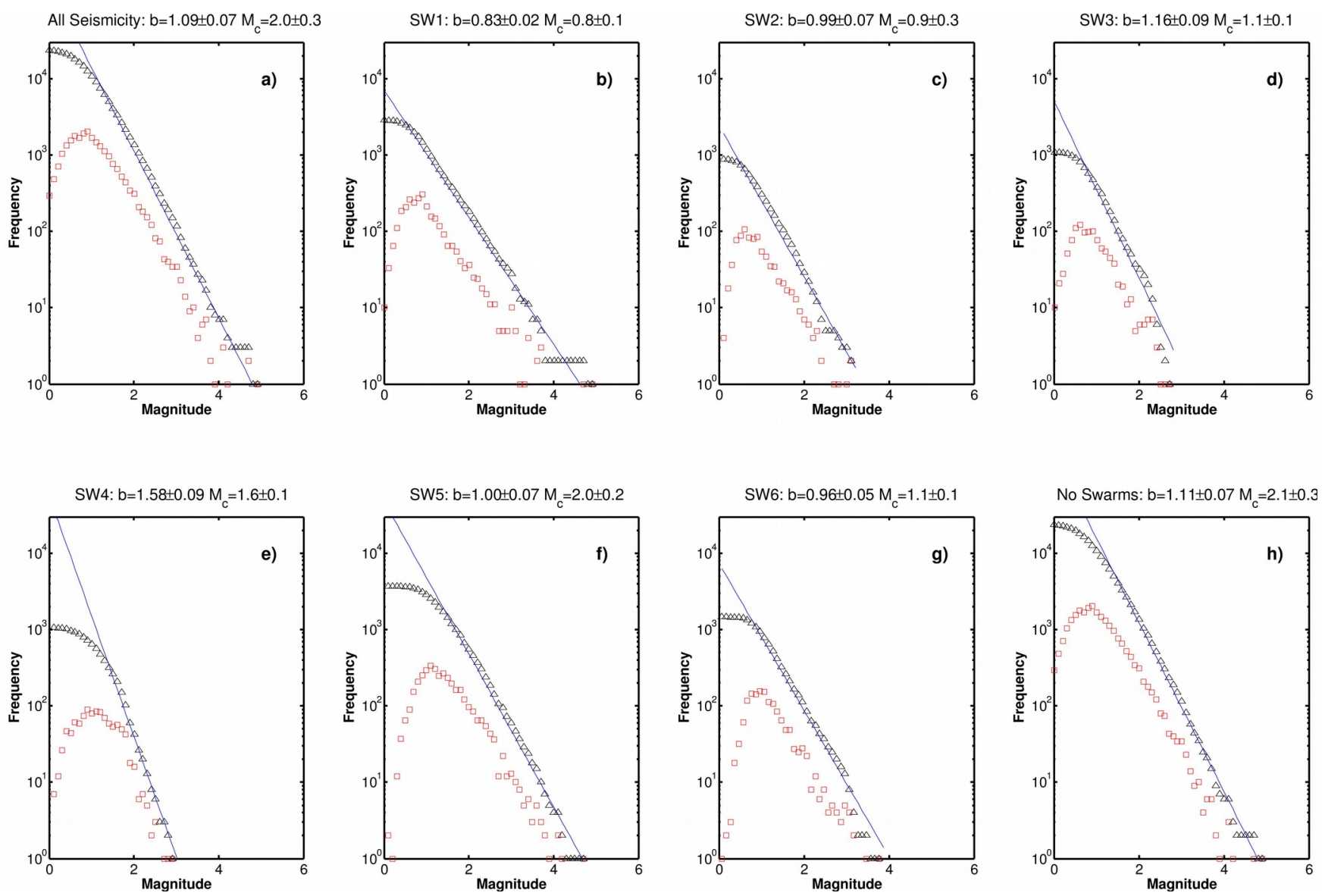

Figure S7: Gutenberg-Richter (GR) fit for seismicity along HFF and ER. Panel a) GR fit for al seismicity. Panels b) to g) GR fit for the swarms SW1 to SW6 analysied in this study. Panel h) GR fit for the remeaining seismicity when the swarms SW1-6 are removed. The fit is performed using the b-stability method and errors on b-values and completeness magnitude $\mathbf{M}_{\mathrm{c}}$ 's are standard deviation of the distribution of parameters after bootstrapping the earthquake catalog 2000 times. All seismicity along HFF and ER show a b-value compatible with 1, which is the value we choose for the ETAS analysis in the text. The completeness magnitude ranges between 1.5 and 2 as discussed in the main text. Each of identified swarm shows almost all a b-value compatible with 1 except for the lower values of SW1 and higher value of SW4. In Panel h) we performed a GR fit for the rest seismicity when the swarms are removed and the b-value is consistend with one. 

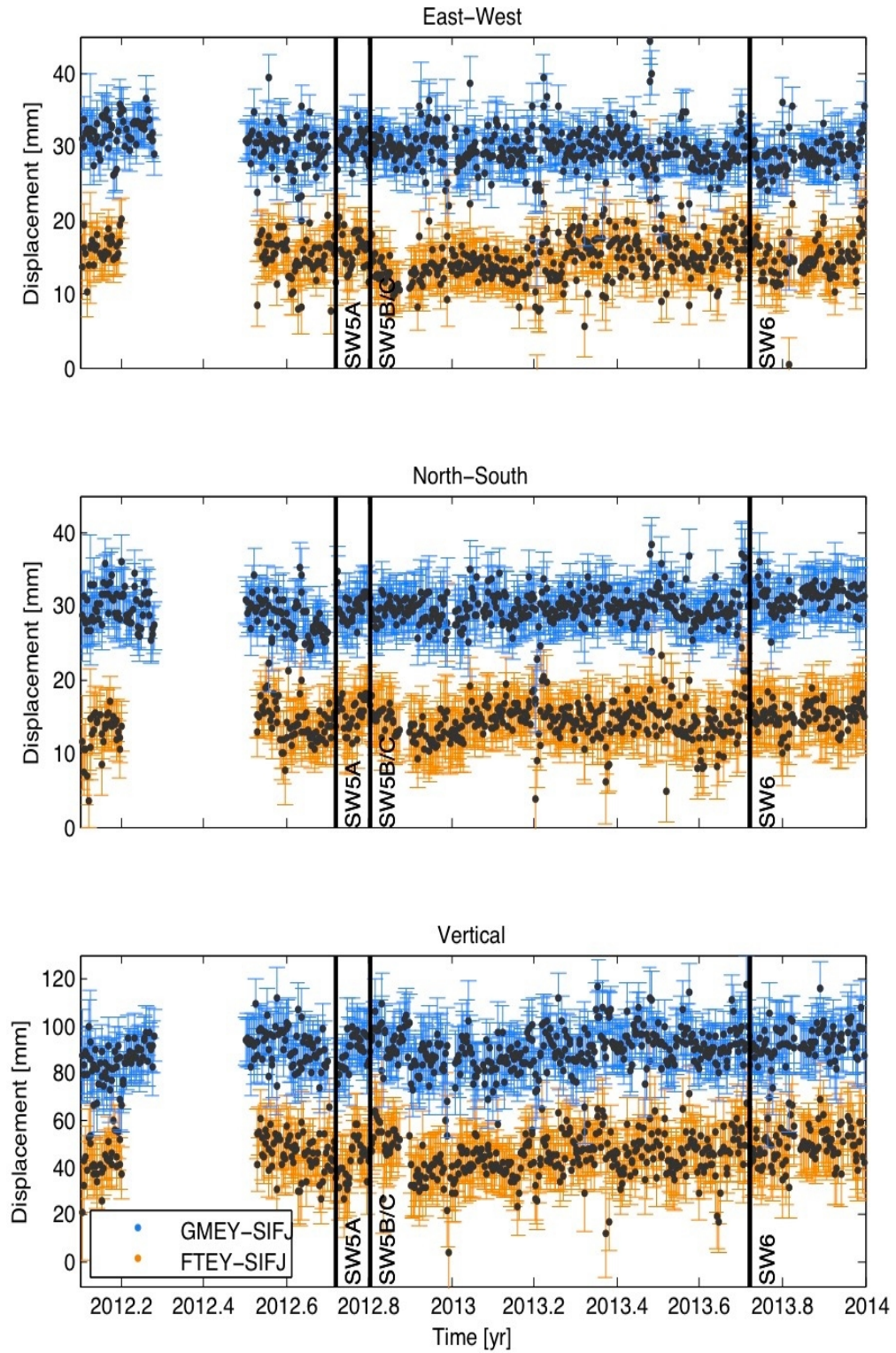

Figure S8: GPS-baselines from the station SIFJ to stations GMEY (blue) and FTEY (orange) for horizontal and vertical components (see Fig. 1 for station locations). No significant baseline changes were caused by the earthquake swarms SW5 (A, B, and C) and SW6 (indicated by vertical black lines). The GPS time-series were corrected for antenna offsets, seasonal oscillation signals and interseismic (linear) trends. 